\title{
Chapter 6 \\ Role of Inorganic Soil Constituents in Selected Topics
}

\begin{abstract}
Three topics are introduced to exemplify the important roles of inorganic soil constituents - the effects of tsunami on soil in Japan in 2011, the dynamics of radiocesium in the soil environment, and phosphates related to a soil-plant system. With respect to tsunami inundation into paddy field soils, soil erosion by seawater flow, sedimentation of soil transported by the seawater flow, precipitation of evaporites, and sodification are discussed. Removal of the deposited sediments and soil washing by rain and irrigation water were effective for restoration of the salt-affected farmlands. Radiocesium was effectively trapped by soil, which regulated its transfer to agricultural products. Among inorganic soil constituents, weathered biotite has a high fixation capacity for radiocesium. The biotite might have been released from granitic rock and volcanic ash. Apatite is the key phosphate in both natural and farmland soils, although it is converted to more soluble forms in the fertilizer industry. Fixation of phosphate by active Al materials is so high in Andisols that the recovery of phosphate by agricultural crops is low, and phosphate accumulation in plow layer soil is continuing. Struvite plays a role in cycling phosphate in the soilplant system of farmlands.
\end{abstract}

\subsection{Introduction}

The inorganic constituents of soil play important roles in providing ecological services, as described in Chap. 1. The major inorganic constituents in soil were outlined in Chaps. 2, 3, 4 and 5. This final chapter is an attempt to exemplify the functioning of various soil inorganic constituents in different cases. Three topics are addressed in the chapter: the huge tsunami that occurred in northeastern Japan in 2011 including ion exchange reactions, the behavior of radiocesium in the soil environment including $\mathrm{Cs}^{+}$fixation, and reactions of phosphate with soil inorganic constituents. Some evaporites and phosphates that were not discussed in the previous chapters are introduced in relation to these topics. 


\subsection{Effects of Tsunami on Soils}

"Tsunami" is a Japanese word that literally means harbor wave. A tsunami forms as the result of a conveyance of a sudden movement of the seafloor, an earthquake, to a huge amount of water, as shown schematically in Fig. 6.1a. The difference between a tsunami and a typical wave caused by strong wind or low atmospheric pressure is that the whole water column, from surface to bottom, moves in the former, whereas only surface water moves in the latter. Even if a tsunami is not very high in the deep ocean, it becomes large when it reaches a shallow harbor.

A magnitude 9.0 earthquake struck eastern Japan on March 11, 2011 (Norio et al. 2011). It triggered a huge tsunami, as shown in Fig. 6.1b, c. The area of farmland damaged by this tsunami is summarized in Fig. 6.2 and Table 6.1. Miyagi Prefecture was damaged most extensively. The tsunami penetrated as much as several kilometers inland from the coastline of Miyagi Prefecture. The damaged farmland consisted mainly of paddy fields (Table 6.1).

\subsubsection{Survey and Analyses of the Tsunami-Affected Soils in Miyagi Prefecture}

A wide area covering almost all of the farmland affected by the huge tsunami on the Pacific coast of Miyagi Prefecture was surveyed from May 11 to 19, 2011
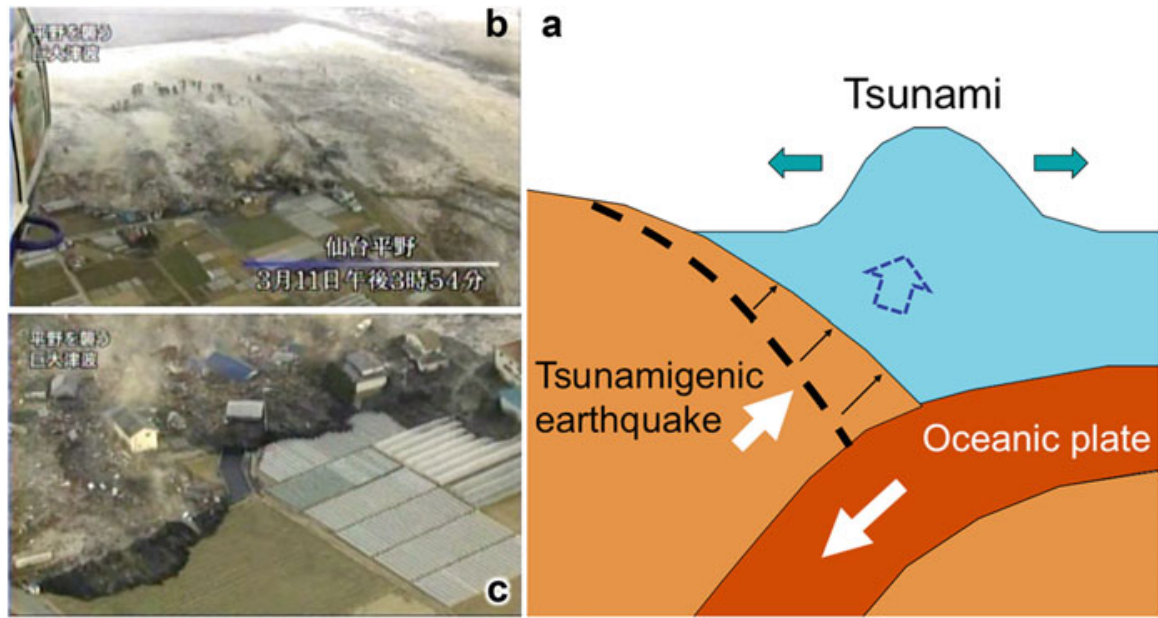

Fig. 6.1 Tsunami on March 11, 2011. (a) Schematic diagram showing the generation of the tsunami, (b) non-colored tsunami inundating land. (from NHK TV news), (c) change in the color of the tsunami when it fell down from the ridge. (From NHK TV news) 
Fig. 6.2 Locations of prefectures where the Pacific coast was affected by the large 2011 tsunami

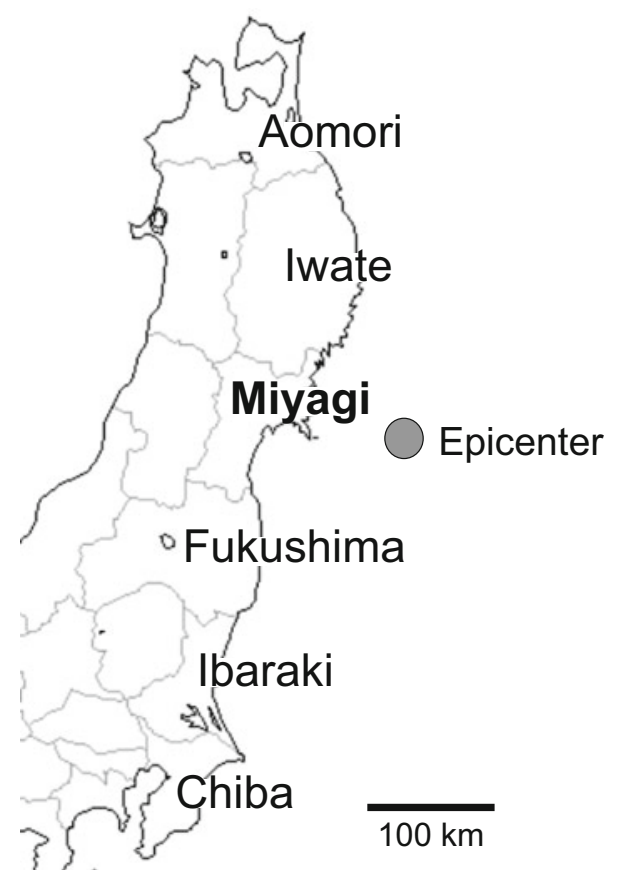

Table 6.1 Estimated areas affected the tsunami

\begin{tabular}{l|l|l|l}
\hline \multirow{2}{*}{ Prefecture } & \multirow{2}{*}{ ha } & Paddy field & Upland \\
\cline { 3 - 4 } & 79 & ha & ha \\
\hline Aomori & 1,838 & 76 & 3 \\
\hline Iwate & 15,002 & 1,172 & 666 \\
\hline Miyagi & 5,923 & 5,588 & 2,317 \\
\hline Fukushima & 531 & 525 & 335 \\
\hline Ibaraki & 227 & 105 & 6 \\
\hline Chiba & 23,600 & 20,151 & 122 \\
\hline Total & & & 3,449 \\
\hline
\end{tabular}

Ministry of Agriculture, Fishery and Forestry, Japan (2012)

(Kanno 2017). The area had a total of 70-100 mm of rain during the 2 months following the tsunami inundation of the farmland.

The total number of sampling sites was 344 fields chosen mostly from the tsunami-affected farmland. For each field, samples taken from the same layer at two separate locations were mixed to represent the field. Based on the preliminary survey, the following procedure for sampling tsunami deposits and underlying soils was determined. If the thickness of the tsunami deposit was $1 \mathrm{~cm}$ or more, the tsunami deposit was sampled separately from the underlying original soil. If the tsunami deposit could be separated into sandy and muddy deposits, these deposits were sampled separately. The original soil was sampled from two layers, 0 to $10 \mathrm{~cm}$ (original soil 1) and 10 to $20 \mathrm{~cm}$ (original soil 2) from the boundary between the 
tsunami deposit and the top of the original soil. The boundary between the tsunami deposit and the original soil was evident because the bottom of the tsunami deposit had a coarse texture, because sands settle faster than finer particles in a soil suspension, and the top of the original soil had a comparatively finer texture (Fig. 6.4c).

After air-drying the tsunami deposit and original soil samples, the samples were ground gently in a porcelain mortar and passed through a $2 \mathrm{~mm}$ sieve to prepare a fine earth fraction. As a result, the samples were mostly passed through the $2 \mathrm{~mm}$ sieve. Using these fine-earth fractions, total $\mathrm{C}, \mathrm{N}$, and $\mathrm{S}$ content, $\mathrm{pH}\left(\mathrm{H}_{2} \mathrm{O}\right)$ and $\mathrm{pH}$ $(\mathrm{KCl})$ at the soil:water ratio of $1: 2.5$, electric conductivity at the soil:water ratio of 1:5 (EC(1:5)), the contents of water-soluble $\mathrm{Na}, \mathrm{K}, \mathrm{Ca}$, and $\mathrm{Mg}$ in the 1:5 water suspension, and $\mathrm{NH}_{4}$-exchangeable $\mathrm{Na}, \mathrm{K}, \mathrm{Ca}$, and $\mathrm{Mg}$ were determined. The contents of $\mathrm{NH}_{4}$-exchangeable $\mathrm{Na}, \mathrm{K}, \mathrm{Ca}$, and $\mathrm{Mg}$ were determined by extracting the sample obtained after extraction of water-soluble $\mathrm{Na}, \mathrm{K}, \mathrm{Ca}$, and $\mathrm{Mg}$ with $1 \mathrm{~mol} \mathrm{~L}{ }^{-1} \mathrm{NH}_{4}$ acetate ( $\mathrm{pH} \mathrm{7)}$ twice (Thomas 1982). Entrained solution volume after centrifugation and decantation of water extract was obtained by weight measurement, and the amount of each cation in the entrained solution was subtracted from each total cations found in the $\mathrm{NH}_{4}$ acetate-extract for the calculation of $\mathrm{NH}_{4}$ exchangeable cations.

The tsunami caused severe damage to buildings. However, the physical damage to farmland was not very severe compared to that of buildings, probably because the tsunami affected only the surface of the farmland and a direct hit between tsunami and farmland soil was mostly avoided.

Intensively eroded sites were found on the inland side of the road running along the coast (Fig. 6.3a). The distance between the road and the shoreline was less than $1 \mathrm{~km}$. When the tsunami dropped from the slightly higher road, paddy field soil was excavated and removed. At these sites, the soil removal was greater than several tens of centimeters from the original surface of the paddy fields. Similar soil erosion occurred along ridges (30-40 cm high), as shown in Fig. 6.3b, although the intensity of the erosion at these sites was lower than that along the roads and the plow sole mostly remained. The intensity of soil erosion over the wide surface of farmland was dependent on whether or not the farmland had been plowed. If the soil had not been plowed, erosion was limited and the rice stubble after harvest mostly remained (Nanzyo 2012). In contrast, plowed soil was removed by the tsunami, especially in farmland near the coast. Soil removal was lower in the farmland distant from the coast, even if the land had been plowed.

These interactions between tsunami and farmland are summarized in Fig. 6.3c. Erosion occurred at sites (1), (2), and (3), and deposition occurred at sites (4) and (5). Ion exchange and precipitation reactions occurred as chemical interactions at sites (4) and (5) (Fig. 6.3c). If there was a muddy (sometimes containing sulfides) and/or sandy deposit beneath the shallow seawater or in the nearshore zone (1) including the Teizan canal, the deposits might have been transported to farmland and deposited at sites (4) and/or (5). Moreover, the $A_{p}$ horizon soil, after tilling, was at least partly lost. Thus, the deposits on the farmland also contain the eroded $A_{p}$ horizon soil. The chemical reactions at sites (4) and (5) include the exchange reaction between $\mathrm{Na}^{+}$in 

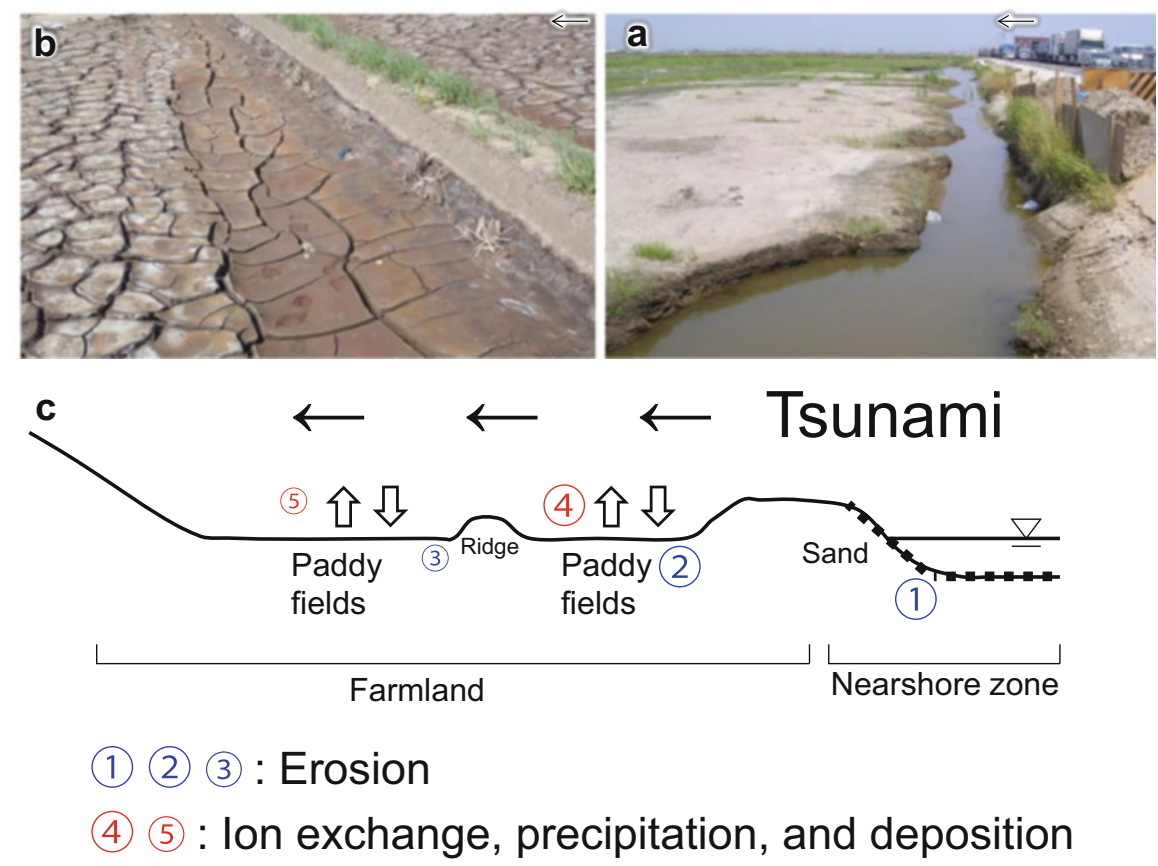

Fig. 6.3 Effects of the tsunami on farmland. (a and b) Erosion and deposition along a road and ridge, respectively, (c) schematic diagram of interactions between tsunami and farmland. Arrows in (a) and (b) show the direction of the tsunami

seawater and exchangeable cations in the $\mathrm{A}_{\mathrm{p}}$ horizon soil and also the precipitation of $\mathrm{CaSO}_{4} \cdot 2 \mathrm{H}_{2} \mathrm{O}$ and $\mathrm{NaCl}$ as the soils became dry.

Figure 6.4a, b show the distribution of the total thickness of the tsunami deposit (mud plus sand) in Miyagi Prefecture and a close-up illustration of the Sendai Bay area, respectively. The total thickness of the tsunami deposit tended to be thicker in the area near the shoreline. The total thickness was very thin or zero near the inland end of the tsunami-affected area. The sandy tsunami deposit was thicker near the shore than in the inland area. The muddy deposit tended to be thick in the intermediate area. Separation of the sandy and muddy deposits is somewhat clear (Fig. 6.4c), possibly because the suspension remained in the paddy field, where the ridge was $30-40 \mathrm{~cm}$ high (Fig. 6.3b).

There was a concern that abundances of toxic elements such as $\mathrm{Cd}, \mathrm{Cu}$, and $\mathrm{As}$ might be excessive in the tsunami deposits. However, according to Miyagi Prefecture, the concentrations of these elements were estimated to be lower than the upper limit established by law for cultivated soils in Japan, except that one mud sample exceeded the limit for As. However, because the thickness of this mud layer was $1 \mathrm{~cm}$ and the exceedance was small, the problem was not considered to be very severe (Shima et al. 2012; Inao et al. 2013). 

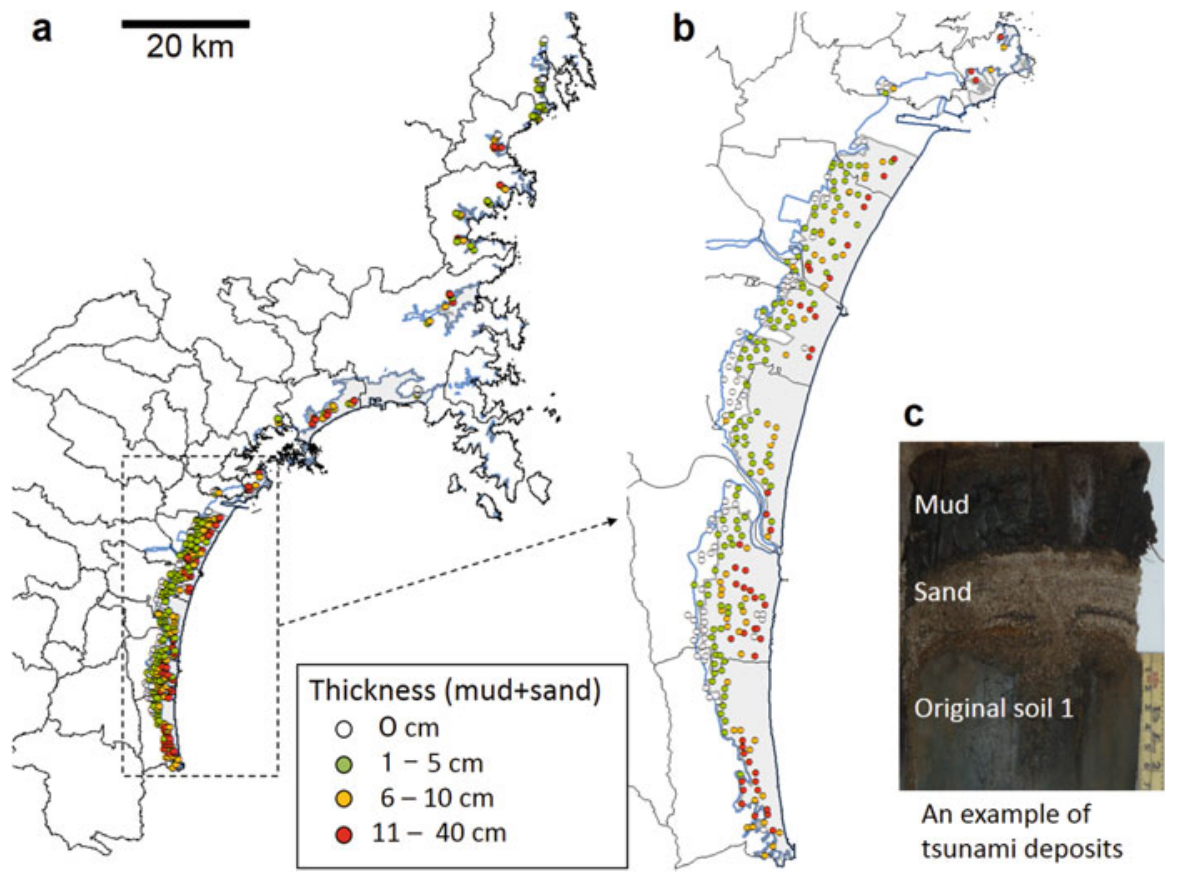

Fig. 6.4 Thickness of the tsunami deposit. (a) Total thickness of mud plus sand in Miyagi Prefecture, (b) close-up illustration of the Sendai Bay area, (c) an example of the tsunami deposit. (Shima et al. 2012; Inao et al. 2013)

Analytical results of the tsunami deposits and the underlying original soils are summarized in Table 6.2. The EC(1:5) values rose with inundation by seawater. Although the highest EC(1:5) values were observed in the muddy tsunami deposit, the original soils showed higher EC(1:5) values than the ordinary soils, indicating that the effects of seawater reached most of the original soil 2 . The total $\mathrm{C}, \mathrm{N}$, and $\mathrm{S}$ content of the muddy tsunami sediment was higher than the content in the sandy tsunami deposits and original soils. Water-soluble and exchangeable $\mathrm{Ca}^{2+}, \mathrm{Mg}^{2+}, \mathrm{K}^{+}$, and $\mathrm{Na}^{+}$content was also high in the muddy tsunami deposit due to the effect of seawater. The EC(1:5) values were highly correlated with the sum of water-soluble $\mathrm{Ca}^{2+}+\mathrm{Mg}^{2+}+\mathrm{K}^{+}+\mathrm{Na}^{+}$on a positive charge basis. Among the four exchangeable cations, the exchangeable sodium percentage (ESP) is used as an index of sodification. In this monograph, the value of 100 times the exchangeable $\mathrm{Na}$ divided by the sum of exchangeable $\mathrm{Ca}^{2+}+\mathrm{Mg}^{2+}+\mathrm{K}^{+}+\mathrm{Na}^{+}$on a positive charge basis is used as ESP. The seawater also affected the $\mathrm{pH}\left(\mathrm{H}_{2} \mathrm{O}\right)$ values. The mean $\mathrm{pH}\left(\mathrm{H}_{2} \mathrm{O}\right)$ values were higher in the muddy and sandy tsunami deposits than in the original soils. Truog P values were higher in the muddy tsunami deposit than in the other deposits. A considerable sulfide concentration in some of the muddy tsunami deposits was suggested from their $\mathrm{pH}\left(\mathrm{H}_{2} \mathrm{O}_{2}\right)$ value of 3 or less (Shima et al. 2012). These results are discussed further below. 


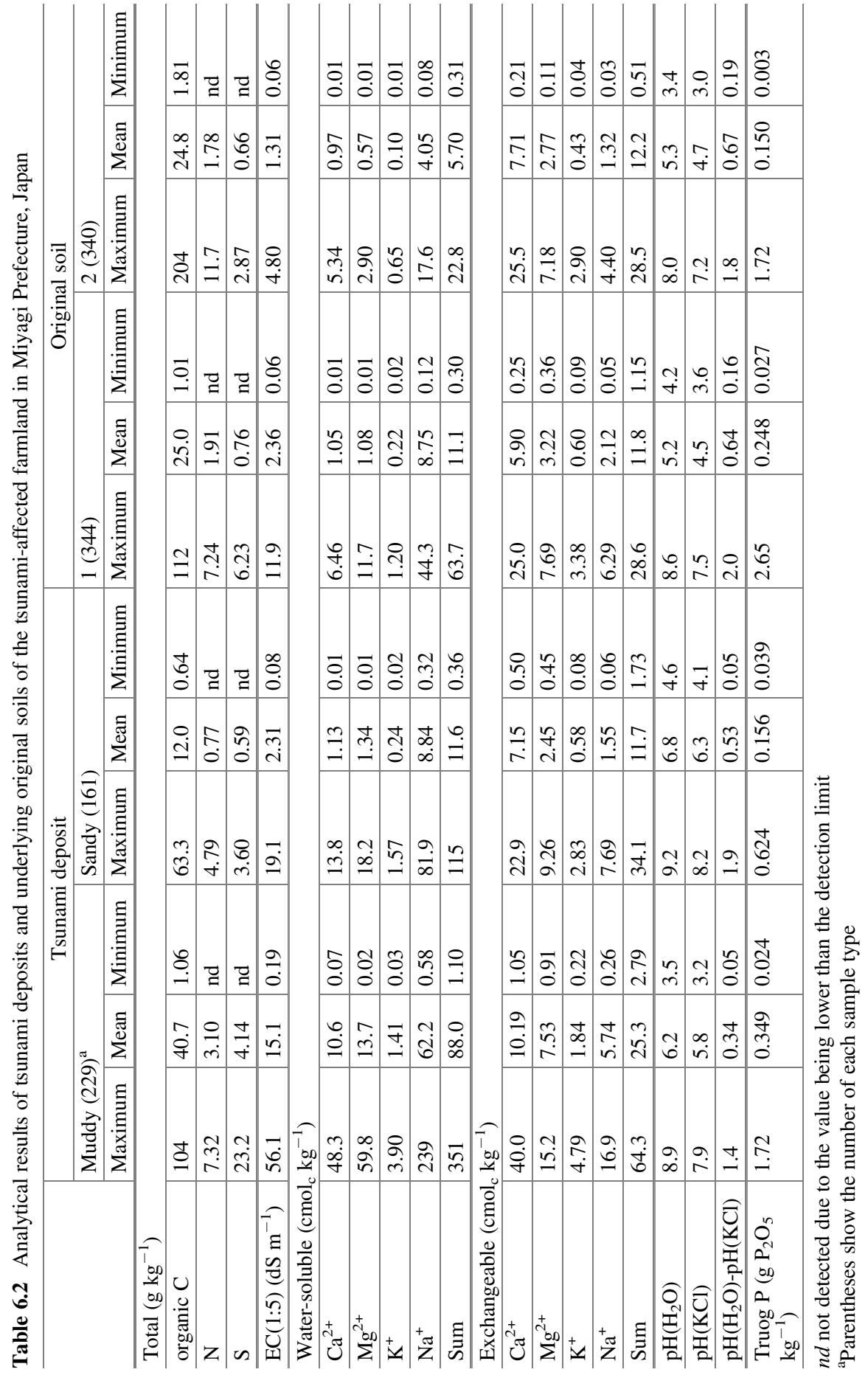




\subsubsection{Origin of the Muddy Tsunami Deposit}

In general, erosion by the tsunami occurred in the nearshore zone (Fig. 6.3 (1)). (Srisutam and Wagner 2010). The color of a tsunami may change from place to place depending on the properties of the sediments on the seafloor. As shown in Fig. 6.1b, the tsunami that struck the Sendai Plain had a whitish color, suggesting that its mud content was low. The color of the tsunami became black when the tsunami crossed over the ridges and flowed down to the paddy fields (Figs. 6.1c and 6.3b). Eroded sites were also found along roads, where the tsunami crossed over the roads and flowed down to the paddy fields (Fig. 6.3a).

The distribution of the total thickness of the tsunami deposit is shown in Fig. 6.4. The sandy tsunami deposit was thicker near the shore, suggesting that most of the sandy tsunami deposit originated in the nearshore zone (Fig. 6.3c (1)). However, the muddy tsunami deposit was thick in the intermediate area of tsunami inundation, so the origin of the muddy tsunami deposit was uncertain. From the distribution of total organic carbon (TOC) content of the muddy deposit shown in Fig. 6.5a, three areas having TOC higher than $4 \%$ can be identified (closed circles). A similar pattern of TOC distribution was found in the original soil 1 (Fig. 6.5b). Furthermore, the soil map of this area showed that TOC-rich soils, such as peat soil and muck soil, are

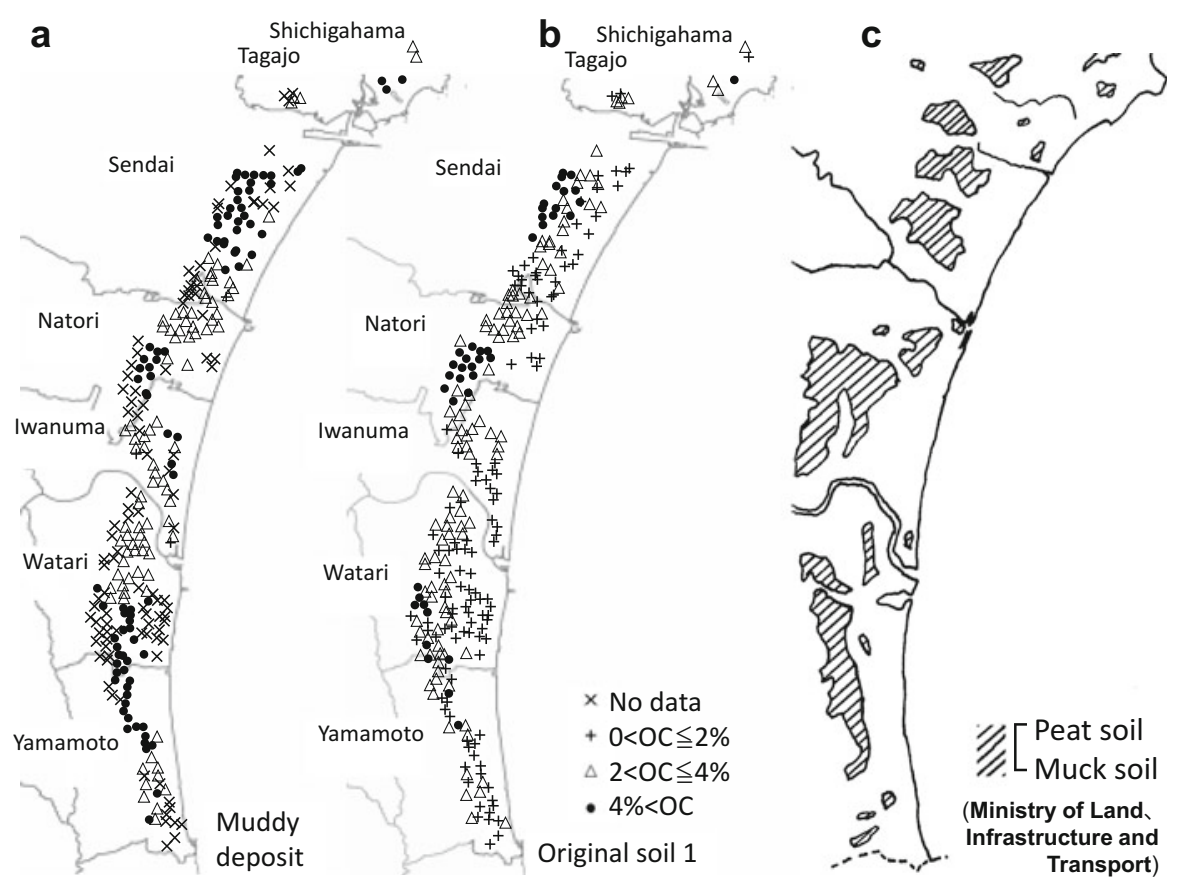

Fig. 6.5 Distribution of total organic carbon (TOC) concentration. (a) Muddy tsunami deposit, (b) underlying original soil 1, (c) soil map showing the distribution of TOC-rich soils (peat and muck soils). The reason for "No data" is that the thickness of the muddy tsunami deposit is very thin 
distributed within the region (shaded areas in Fig. 6.5c). Hence, the TOC-rich areas of the muddy tsunami deposits are nearly identical to those of the original soil 1 and the soil map made before tsunami inundation. Considering these results, it is highly probable that the muddy tsunami deposits originated from the surface soil of the tsunami affected areas. This estimation is supported by the fact that the Truog P values of the muddy tsunami deposits are distinctively higher than those of the sandy tsunami deposit and original soils 1 and 2 (Table 6.2). The high Truog P values are due to the accumulation of $\mathrm{P}$ fertilizer in the plow layer soil. The plow layer soil of the farmland eroded by the tsunami was deposited with sorting as the tsunami retreated. Szczuciński et al. (2012) reported that marine sediments are present in only low abundance in the present muddy tsunami deposit on the Sendai Plain.

\subsubsection{Relationships Between TOC, TN, and TS of the Tsunami Deposits and the Original Soils}

The abundance of sulfides in the tsunami deposits was one of the concerns about the deposits. Total sulfur (TS) content was determined in addition to TOC and total nitrogen (TN) because acidification can occur after oxidation. The relationship between TOC and TS is plotted with TN in Fig. 6.6. In general, there is a close relationship between TOC and TN for both the muddy tsunami deposit and the original soil 2. A linear relationship was also found between the TOC and TS content of the original soil 2 , suggesting that a major portion of the sulfur is in organic forms
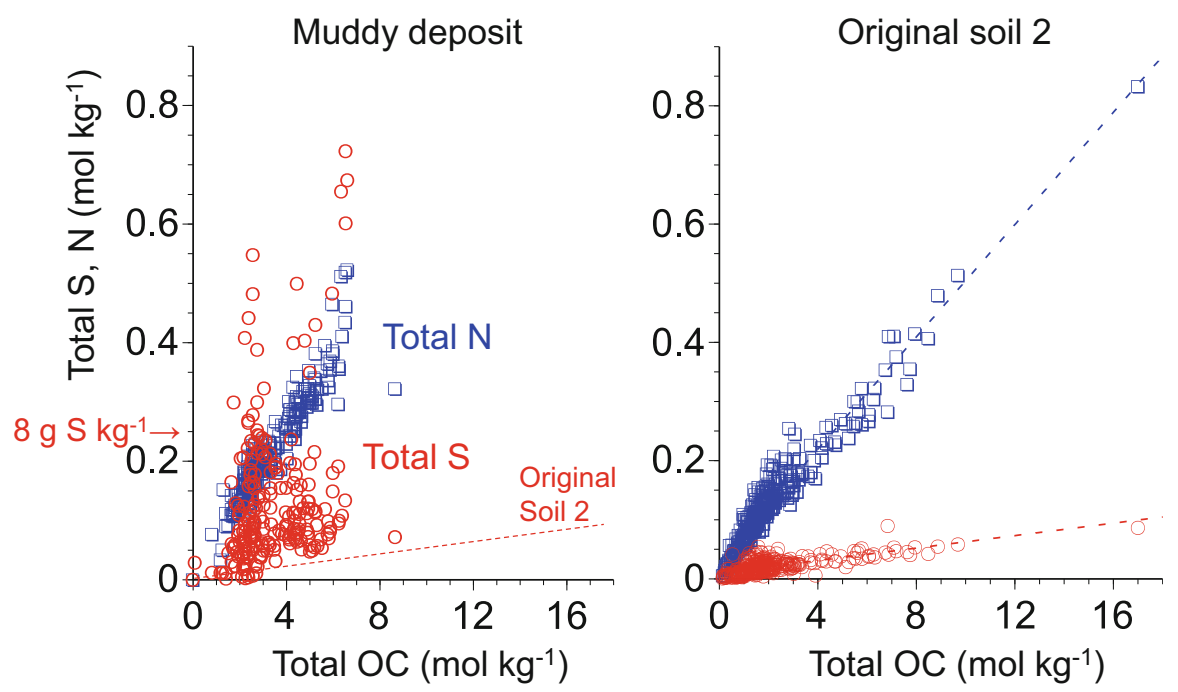

Fig. 6.6 Relationships between total organic $\mathrm{C}$ content and total $\mathrm{N}$ and $\mathrm{S}$ content of the muddy tsunami deposit and original soil 2 , respectively 
(Erickson 2009). In contrast, the TS content of the muddy tsunami deposit was larger than the content of original soil 2 by various amounts. Because the TS content of the muddy tsunami deposit does not correlate with TOC, the added TS (beyond that of original soil 2) appears to be in inorganic form. The four samples from TS-rich muddy tsunami deposits all included framboidal pyrite, as shown in Figs. 5.26 and 5.27 .

\subsubsection{Evaporites on the Tsunami Deposits}

White powdery materials, possibly evaporites, formed on the surface of the muddy tsunami deposits, as shown in Fig. 6.3b. A sample was taken from one muddy tsunami deposit (Fig. 6.7a) and was examined using SEM-EDX and XRD. Halite and gypsum were identified, as shown in Fig. 6.7. The halite particles showed cubic form (Fig. 6.7b) and the gypsum crystals were prismatic (Fig. 6.7c) under the SEM. The elemental compositions of the halite and the gypsum were confirmed by EDX spectra, as shown in Fig. 6.7d, e, respectively. According to the XRD data, gypsum

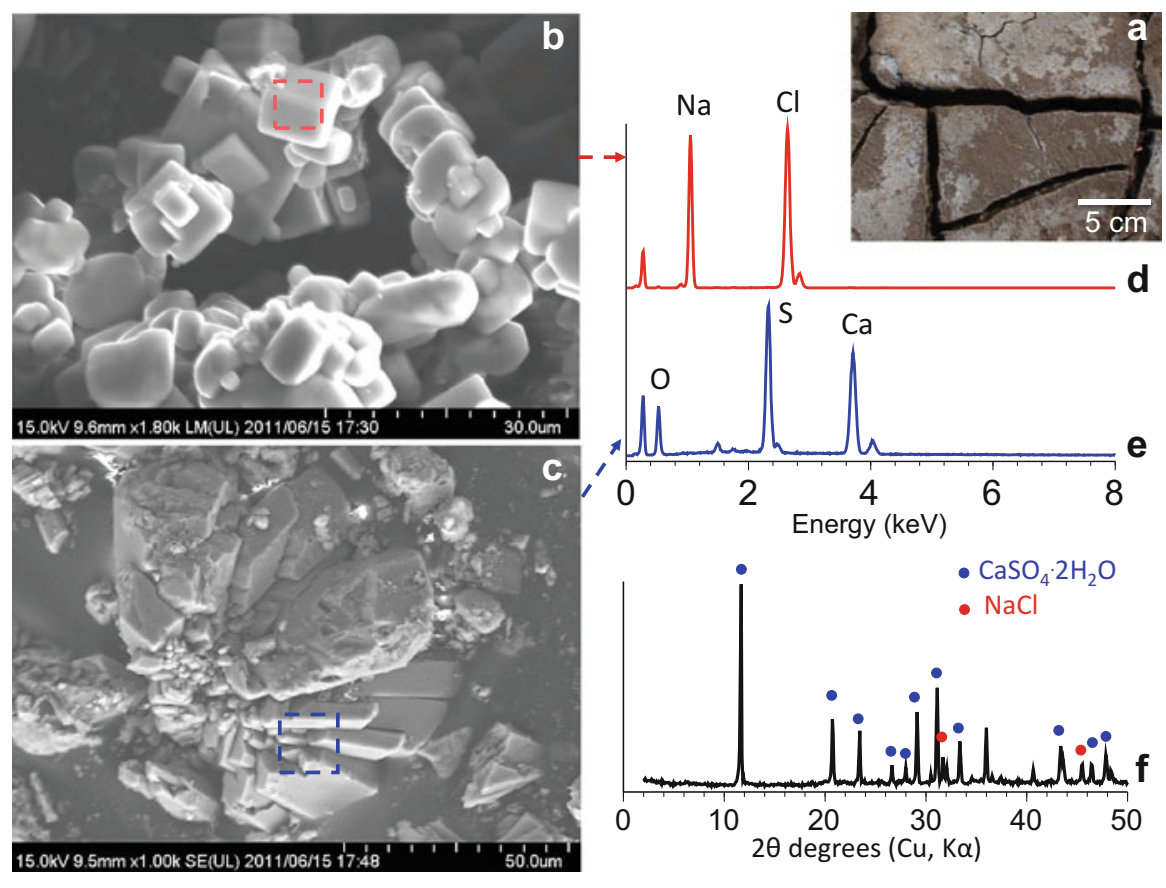

Fig. 6.7 Evaporites formed on the surface of the muddy tsunami deposit. (a) Optical photograph of the muddy tsunami deposit having evaporites, (b and c) SEM images of halite and gypsum, respectively, (d and e) EDX spectra of the dashed squares in (b) and (c), respectively, (f) XRD pattern of the evaporites 
appears to be the major constituent in this sample (Fig. 6.7f). This result is due to the lower solubility of gypsum than halite. At the sampled site, a considerable portion of the halite had been removed by rainwater, leaving the gypsum as the major evaporite. Gypsum can precipitate from seawater during drying. In addition, $\mathrm{Ca}^{2+}$, released from the Ap horizon soil by an ion exchange reaction with $\mathrm{Na}^{+}$, could take part in the gypsum precipitation because $\mathrm{SO}_{4}{ }^{2-}$ is relatively abundant in seawater.

Further study for evaporates is Doner and Lynn (1989).

\subsubsection{Salinization and Sodification}

The major chemical effects of tsunami inundation are salinization and sodification of soils (Fig. 6.8). Salinization is an increase in the concentration of water-soluble salts to a level detrimental to mesophytes or most crop plants. Saline soil is defined by an EC value of $4 \mathrm{dS} \mathrm{m}^{-1}$ using saturation extract. It roughly corresponds to an EC(1:5) value of $0.6 \mathrm{dS} \mathrm{m} \mathrm{m}^{-1}$. Sodic soil is defined by an ESP value of $15 \%$ or more. Soils having both saline and sodic properties are saline-sodic soils. Typical farmland soils have exchangeable and water-soluble ionic compositions of $\mathrm{Ca}^{2+}>\mathrm{Mg}^{2+}>\mathrm{K}^{+} \simeq \mathrm{Na}^{+}$ on a charge basis. The occurrence of a tsunami changes this ionic composition. With an increase in ESP, clay particles tend to disperse in water and become hard clods after drying.

According to the mean EC(1:5) values (Table 6.2), the extent of salinization was in the order of muddy tsunami deposits $>$ sandy tsunami deposits $\simeq$ original soils $1>$ original soils 2 . The mean ESP value was highest in the muddy tsunami deposits and lowest in the original soils 2 among the four groups of samples. Changes in the charge fractions of exchangeable $\mathrm{Ca}^{2+}, \mathrm{Mg}^{2+}$, and $\mathrm{K}^{+}$compared with that of $\mathrm{Na}^{+}$for original soil 2, which showed a wide range of salinization and sodification, are plotted in Fig. 6.9. An increase in the charge fraction of exchangeable $\mathrm{Na}^{+}$indicates an increasing effect of seawater. The charge fraction of $\mathrm{Ca}^{2+}$ deceased with an increase of charge fraction of $\mathrm{Na}^{+}$, and the charge fractions of $\mathrm{Mg}^{2+}$ and $\mathrm{K}^{+}$ increased slightly with that of $\mathrm{Na}^{+}$. These results are similar to those for the muddy and sandy tsunami deposits and original soil 1, although the slopes of the

Fig. 6.8 Schematic diagram showing seawater inundation to soil

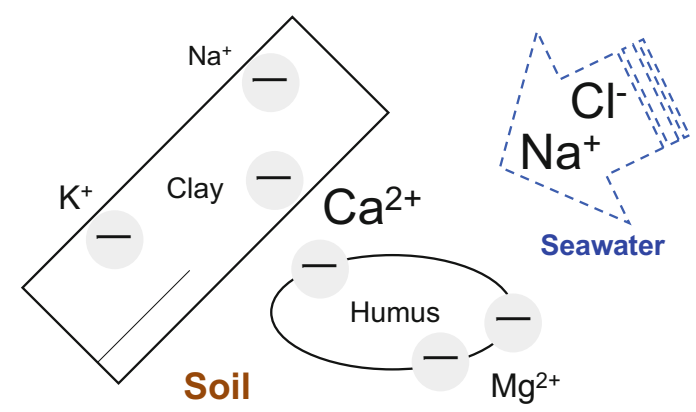




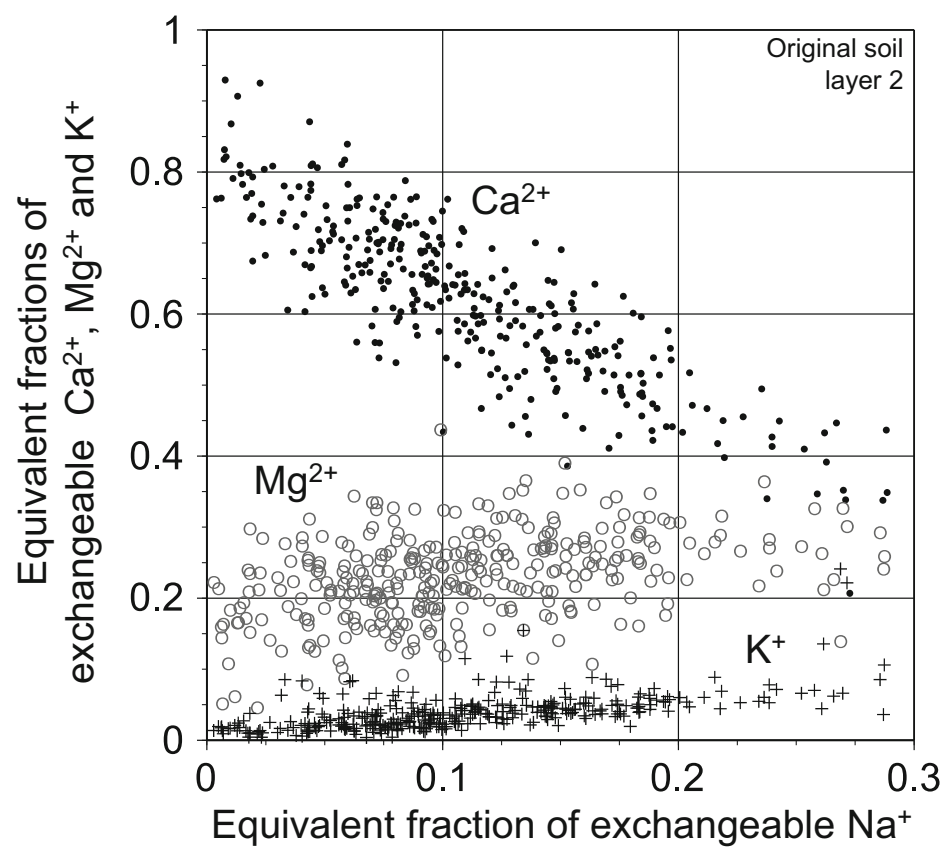

Fig. 6.9 Changes in charge fractions of exchangeable $\mathrm{Ca}^{2+}(\cdot), \mathrm{Mg}^{2+}(\mathrm{O})$, and $\mathrm{K}^{+}(+)$with exchangeable $\mathrm{Na}^{+}$, of original soil 2

plot distributions are slightly diverse. The changes in the charge fractions of exchangeable cations are related to those ions in the solution phase in Figs. 6.10 and 6.11 .

The relationships of the charge fractions of the four ions $\left(\mathrm{Ca}^{2+}, \mathrm{Mg}^{2+}, \mathrm{K}^{+}\right.$, and $\left.\mathrm{Na}^{+}\right)$ between water-soluble (1:5 water extract) and exchangeable forms are plotted in Fig. 6.10. The charge fraction of exchangeable $\mathrm{Na}^{+}$increased gradually with an increase in the charge fraction of water-soluble $\mathrm{Na}^{+}$, whereas the charge fraction of exchangeable $\mathrm{Ca}^{2+}$ decreased steeply with a decrease in the charge fraction of watersoluble $\mathrm{Ca}^{2+}$. Although the distribution ranges of the charge fractions of $\mathrm{K}^{+}$and $\mathrm{Mg}^{2+}$ are narrower than those of $\mathrm{Na}^{+}$and $\mathrm{Ca}^{2+}$, the charge fractions of exchangeable $\mathrm{K}^{+}$and $\mathrm{Mg}^{2+}$ increased with increases in the charge fractions of water-soluble $\mathrm{K}^{+}$and $\mathrm{Mg}^{2+}$. These cation exchange reactions suggest that the high charge fraction of exchangeable $\mathrm{Ca}^{2+}$ for soils weakly affected by seawater is due to the high charge fraction of water-soluble $\mathrm{Ca}^{2+}$.

The relationship between the water-soluble and exchangeable cations of the muddy tsunami deposit (Fig. 6.11) lacks high charge fraction plots of both watersoluble and exchangeable $\mathrm{Ca}^{2+}$ and low charge fraction plots of both water-soluble and exchangeable $\mathrm{Na}^{+}$in comparison with those for original soil 2 (Fig. 6.10). In Fig. 6.11, under the high charge fraction of water-soluble $\mathrm{Na}^{+}$, the charge fractions of exchangeable $\mathrm{Ca}^{2+}$ and $\mathrm{Mg}^{2+}$ still maintain slightly higher levels than those of exchangeable $\mathrm{Na}^{+}$. Plots similar to those of Fig. 6.11 were obtained from the sandy 


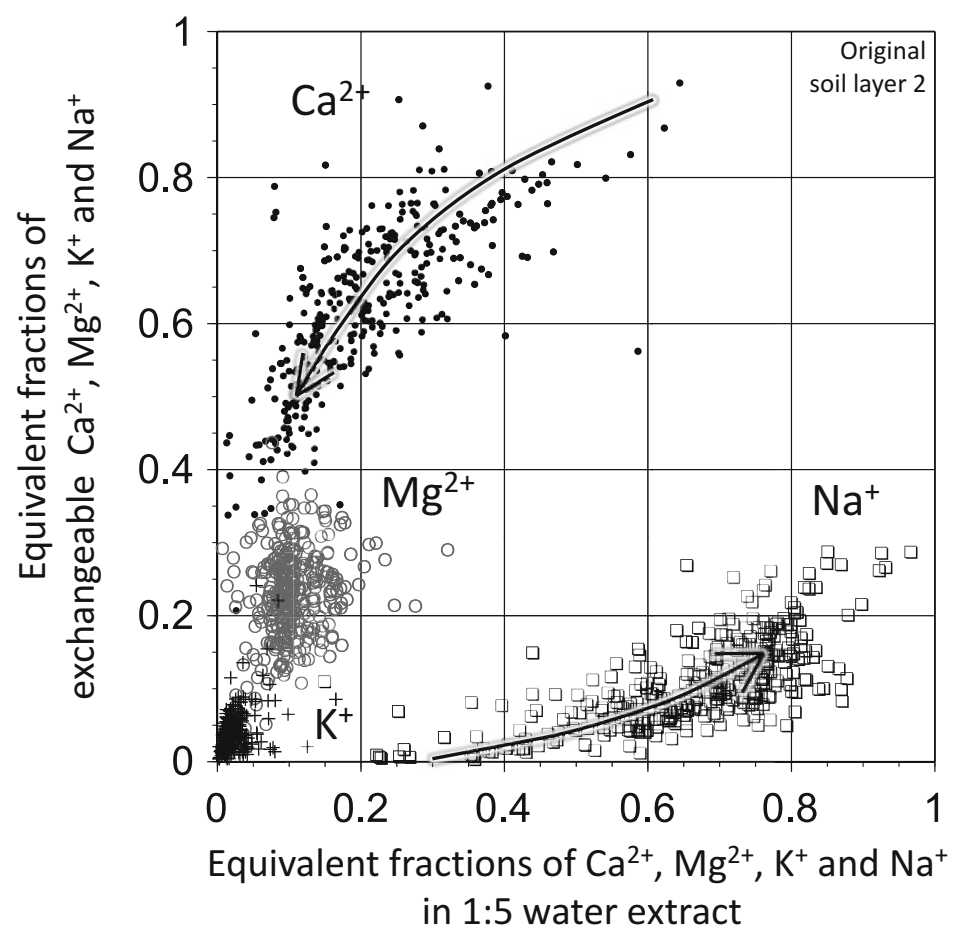

Fig. 6.10 Relationships between the charge fractions of water-soluble and exchangeable $\mathrm{Ca}^{2+}(\cdot)$, $\mathrm{Mg}^{2+}(\mathrm{O}), \mathrm{K}^{+}(+)$, and $\mathrm{Na}^{+}(\square)$, respectively, of original soil 2

tsunami deposit, and plots intermediate between those of Figs. 6.10 and 6.11 were obtained from original soil 1. Although the details of the high TS content (percentages of pyrite, gypsum, and organic forms) of the muddy tsunami deposit were not determined, dissolution of gypsum might have affected the water-soluble and exchangeable $\mathrm{Ca}^{2+}$ content to some extent. The charge fraction of exchangeable $\mathrm{Na}^{+}$ hardly rises to 0.5 or more under these conditions.

The cation exchange properties observed in the present tsunami-affected deposits and soils were compared with those of previous observation. The U.S. Salinity Laboratory used the following equation for a number of different soils and reported that the $\mathrm{K}_{\mathrm{G}}$ was 0.01475 (mmol L $\left.^{-1}\right)^{-0.5}$ (Kamphorst and Bolt 1976).

$$
\mathrm{ESP} /(100-\mathrm{ESP})=\mathrm{K}_{\mathrm{G}} \times \mathrm{SAR}
$$

$\mathrm{SAR}($ sodium absorption ratio $)=$ Water-soluble $\mathrm{Na}^{+} /\left(\text {Water-soluble } \mathrm{Ca}^{2+}+\mathrm{Mg}^{2+}\right)^{0.5}$

In the above, water-soluble $\mathrm{Na}^{+}, \mathrm{Ca}^{2+}$, and $\mathrm{Mg}^{2+}$ are expressed as $\left(\mathrm{mmol} \mathrm{L}^{-1}\right)$ in 1:5 water extraction.

The relationship between the left side and the SAR of Eq. 6.1 is examined in Fig. 6.12. The $\mathrm{K}_{\mathrm{G}}$ value of 0.015 is also shown in Fig. 6.12 by a dashed line. Although the scattering of plots is larger than the scattering reported by the 


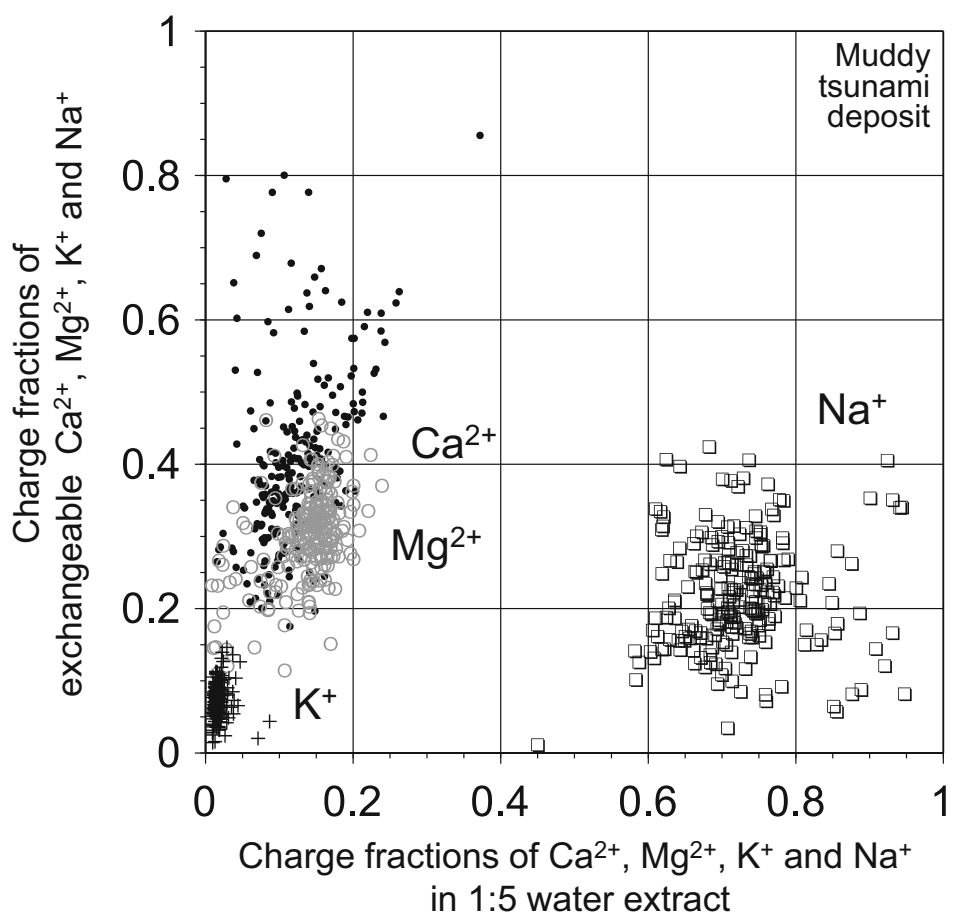

Fig. 6.11 Relationships between the charge fractions of water-soluble and exchangeable $\mathrm{Ca}^{2+}(\cdot)$, $\mathrm{Mg}^{2+}(\mathrm{O}), \mathrm{K}^{+}(+)$, and $\mathrm{Na}^{+}(\square)$, respectively, of the muddy tsunami deposit

U.S. Salinity Laboratory (1954), the plots are distributed around the $\mathrm{K}_{\mathrm{G}}$ value of 0.015. Possible reasons for deviation of the plots from $\mathrm{K}_{\mathrm{G}}=0.015$ are (i) the effect of gypsum dissolution on the water-soluble $\mathrm{Ca}^{2+}$ and exchangeable $\mathrm{Ca}^{2+}$ of the muddy tsunami deposit and (ii) the widely different soluble cation concentration expressed by the broad range of EC(1:5) values (Table 6.2). The clay mineral composition of the area is a mixture of smectite, vermiculite, and kaolin minerals. As widely different $\mathrm{K}_{\mathrm{G}}$ values have been reported for different pure clay minerals, the almost constant values for many soils might be due to mixed clay mineral compositions (Shainberg et al. 1980; Miller et al. 1990; Kopittke et al. 2006; Endo et al. 2002). Because the average SAR of the river water used for irrigation of the tsunami-affected area is $0.6\left(\mathrm{mmol} \mathrm{L}^{-1}\right)^{0.5}$ and the calculated ESP value using Eq. (6.1) is $0.9 \%$, it is suggested that the ESP values of the tsunami-affected soils will decrease gradually with irrigation by the river water.

Further readings about the cation exchange reactions in soil include Evangelow and Phillips (2005) and McBride (1989). 


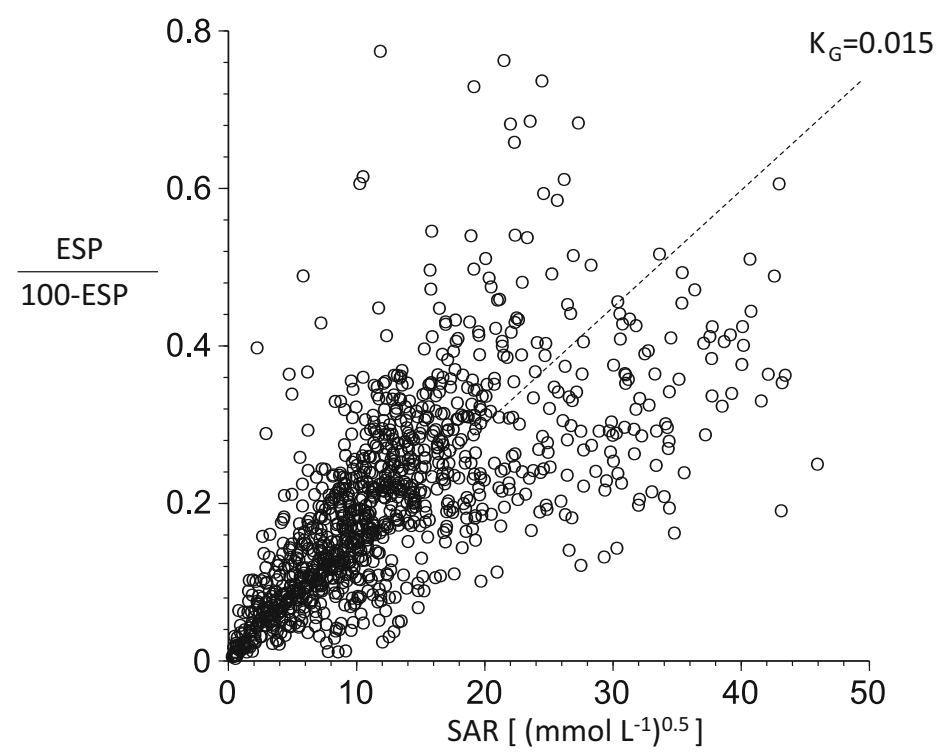

Fig. 6.12 Relationship between SAR and ESP/(100 - ESP) of the tsunami deposits and original soils 1 and 2 . The dashed line shows the $K_{G}$ value of 0.015 . The number of samples is 1074

\subsubsection{Variation in pH of Tsunami Deposits and Original Soils}

Soil $\mathrm{pH}$ is one of the important variables which relate with many other soil properties. The $\mathrm{pH}\left(\mathrm{H}_{2} \mathrm{O}\right)$ values of the air-dried fine-earth fraction of paddy field soils in Japan typically ranges between 5.4 and 5.9 (Oda et al. 1987). The pH value of negatively charged soil decreases with the addition of salts, as exemplified by $\mathrm{pH}$ $(\mathrm{KCl})$. As shown in Fig. 6.13a, the frequency distributions of $\mathrm{pH}\left(\mathrm{H}_{2} \mathrm{O}\right)$ values of the tsunami deposits and original soils are different, despite the muddy tsunami deposit being derived mostly from the farmland. The tsunami deposits were suspended once in seawater, which has a salt concentration of approximately $0.6 \mathrm{~mol} \mathrm{~L}{ }^{-1}$. The wide distribution of the $\mathrm{pH}\left(\mathrm{H}_{2} \mathrm{O}\right)$ values is due to differences in subsequent drainage conditions. Under well-drained conditions, the tsunami deposits were effectively washed by rainwater and the $\mathrm{pH}\left(\mathrm{H}_{2} \mathrm{O}\right)$ value became high. This is mainly due to the coordination of $\mathrm{H}^{+}$on the negative variable-charge site with a decrease in the electrolyte concentration in the liquid phase. As a result, $\mathrm{OH}^{-}$remains in the liquid phase and increases the $\mathrm{pH}$ value. The amount of rain between tsunami inundation and soil sampling was 70-100 mm (Fig. 6.13b).

If the drainage was poor after immersion in seawater, the $\mathrm{pH}\left(\mathrm{H}_{2} \mathrm{O}\right)$ value was kept low owing to high salt concentration. As the $\mathrm{pH}(\mathrm{KCl})$ value is determined in $1 \mathrm{~mol} \mathrm{~L}^{-1}$ $\mathrm{KCl}$, which is not very much different from the concentration in seawater, the difference $(\Delta \mathrm{pH})$ between the $\mathrm{pH}\left(\mathrm{H}_{2} \mathrm{O}\right)$ and $\mathrm{pH}(\mathrm{KCl})$ values tended to be small in the majority of the muddy tsunami deposits due to restricted drainage (Table 6.2). In 

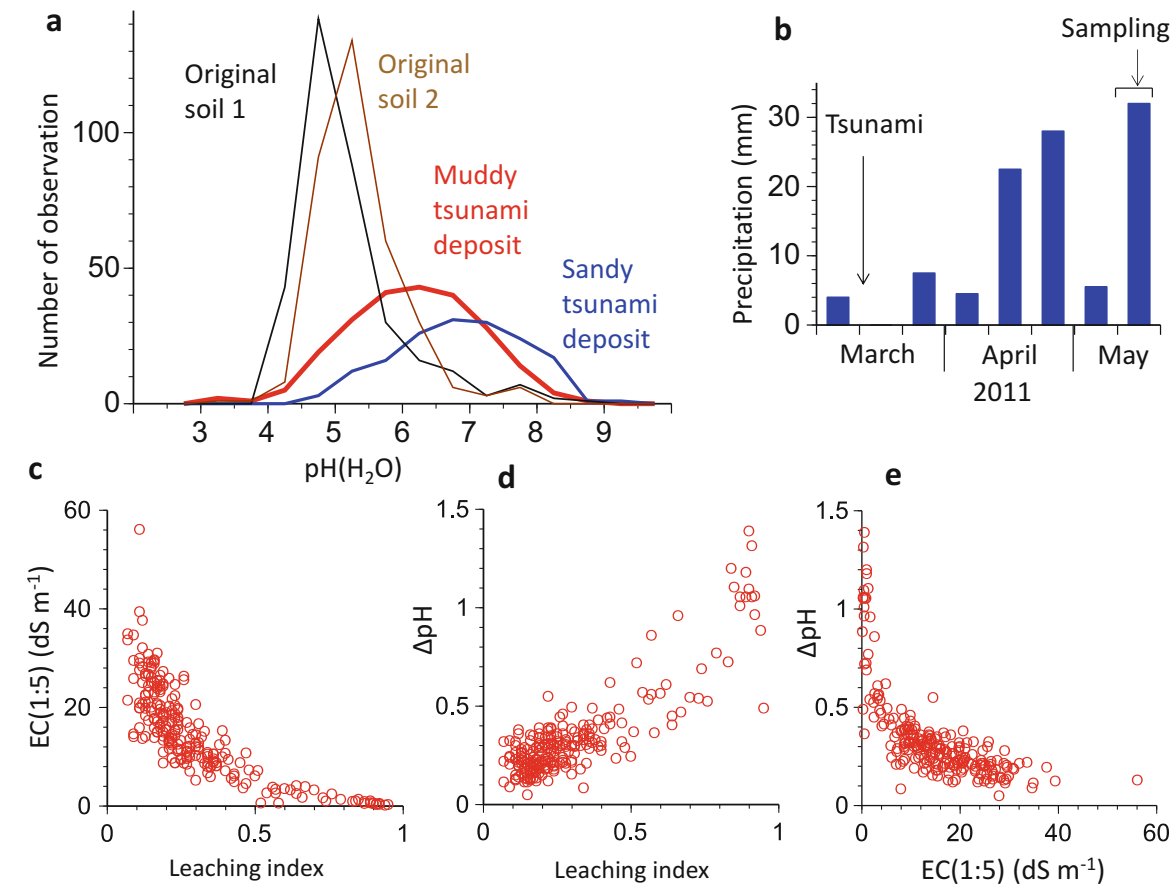

Fig. 6.13 $\mathrm{pH}\left(\mathrm{H}_{2} \mathrm{O}\right)$ values of the tsunami deposits and the original soils. (a) Frequency distributions of $\mathrm{pH}\left(\mathrm{H}_{2} \mathrm{O}\right)$ values of the tsunami deposits and the original soils (for example, a plot at $\mathrm{pH}$ $\left(\mathrm{H}_{2} \mathrm{O}\right)=3.25$ shows the number of observations ranging within $\left.3<\mathrm{pH}\left(\mathrm{H}_{2} \mathrm{O}\right) \leqq 3.5\right)$, (b) precipitation between the day of the tsunami effect and the sampling of the tsunami deposits and original soils, (c) relationship between the sum of exchangeable cations $\left(\mathrm{Ca}^{2+}+\mathrm{Mg}^{2+}+\mathrm{K}^{+}+\mathrm{Na}^{+}\right) /$ (the sum of exchangeable cations $\left(\mathrm{Ca}^{2+}+\mathrm{Mg}^{2+}+\mathrm{K}^{+}+\mathrm{Na}^{+}\right)$plus the sum of water-soluble cations $\left(\mathrm{Ca}^{2+}+\mathrm{Mg}^{2+}+\mathrm{K}^{+}+\mathrm{Na}^{+}\right)$) (leaching index) and $\mathrm{EC}(1: 5)$, (d) relationship between the leaching index and $\left(\mathrm{pH}\left(\mathrm{H}_{2} \mathrm{O}\right)-\mathrm{pH}(\mathrm{KCl})\right)(\Delta \mathrm{pH}),(\mathbf{e})$ relationship between $\mathrm{EC}(1: 5)$ and $\Delta \mathrm{pH}$. All of $(\mathbf{c}),(\mathbf{d})$, and $(\mathbf{e})$ are for the muddy tsunami deposit $(\mathrm{n}=229)$

other words, the $\mathrm{pH}\left(\mathrm{H}_{2} \mathrm{O}\right)$ value can be close to the $\mathrm{pH}(\mathrm{KCl})$ value for samples if the samples were under restricted drainage.

However, a portion of the muddy tsunami deposit must have been under welldrained conditions. The EC(1:5) value decreased steeply with increase in leaching index (Fig. 6.13c). The intensity of drainage or leaching can be expressed numerically by the leaching index, which is tentatively defined as the sum of exchangeable cations $\left(\mathrm{Ca}^{2+}+\mathrm{Mg}^{2+}+\mathrm{K}^{+}+\mathrm{Na}^{+}\right)$divided by the (sum of exchangeable cations $\left(\mathrm{Ca}^{2+}\right.$ $\left.+\mathrm{Mg}^{2+}+\mathrm{K}^{+}+\mathrm{Na}^{+}\right)$plus the sum of water-soluble cations $\left(\mathrm{Ca}^{2+}+\mathrm{Mg}^{2+}+\mathrm{K}^{+}+\mathrm{Na}^{+}\right)$). The leaching index is based on the fact that water-soluble cations are lost easily with rainwater and drainage, whereas exchangeable cations are lost slowly. The $\Delta \mathrm{pH}$ value increased with leaching, as shown in Fig. 6.13d. It was also confirmed that the $\Delta \mathrm{pH}$ of the muddy tsunami deposit is inversely proportional to the $\mathrm{EC}(1: 5)$ value (Fig. 6.13e). 
According to Vorob'eva and Pankova (2008), ESP increased to 50\% or higher when the $\mathrm{pH}\left(\mathrm{H}_{2} \mathrm{O}\right)$ value was 9.5 or higher. Similar results were obtained using selected samples from the muddy tsunami deposit. As a large amount of $\mathrm{Na}_{2} \mathrm{CO}_{3}$ was necessary to raise the ESP values higher than 50\%, it was estimated that the ESP values of the tsunami-affected deposit in the humid region hardly rise higher than $50 \%$.

\subsubsection{Desalinization and Restoration of the Tsunami- Affected Farmland}

The tsunami-affected area is under a humid and temperate climate. Natural rainwater will gradually remove salts from the soil. On the other hand, lowland soils, peat soils, and muck soils are distributed in the region (Fig. 6.5c), and the groundwater level is mostly high. Drainage water was pumped out near the major river mouths of the central and southern part of Miyagi Prefecture, although the pumping system was destroyed by the tsunami. Under these conditions, Figs. 6.14 and 6.15 show an example of the vertical distribution of salts in paddy field with the passage of time. This study site is located $3 \mathrm{~km}$ inland from the shoreline. The EC(1:5) value of the muddy tsunami deposit ( $4 \mathrm{~cm}$ thick) was $9.2 \mathrm{dS} \mathrm{m}^{-1}$ on June 15, 2011 (Fig. 6.14a), and a portion of salts reached a depth of $36 \mathrm{~cm}$ from the surface. This date was 3 months after the tsunami, and a total of $250 \mathrm{~mm}$ of rainwater had fallen. The EC (1:5) values of the tsunami deposit and the Ap horizon soil were lowered to around 1.5-2 dS m ${ }^{-1}$ by September 4, 2011 (Fig. 6.14b), by natural rainwater (Fig. 6.14d). Although the tsunami deposit was removed from the paddy field after this time, the $\mathrm{EC}(1: 5)$ values were reduced further to values lower than $0.6 \mathrm{dS} \mathrm{m}^{-1}$, a safe level for mesophytes, by natural rainwater to the depth of $20 \mathrm{~cm}$ by June 24, 2012 .

After removal of the soluble salts in the liquid phase by natural rainwater, $\mathrm{Na}^{+}$ held on the exchange sites of the soil still tended to remain (Fig. 6.15b, c) whereas EC(1:5) values were lowered (Fig. 6.14c). The low exchangeable $\mathrm{Na}^{+}$values at the depth of around 30-40 cm are due to the insertion of a sand layer (Fig. 6.16a).

To restore the farmland damaged by the tsunami, debris from damaged homes, fallen trees, and excessive salts had to be removed. The tsunami deposits have also been removed from the farmland in Miyagi Prefecture. A portion of the Ap horizon may have been removed during this operation. Irrigation water was finally used to remove salts to a safe level. Soil from nearby mountains was dressed to refill the original farmland level. A reduction in soil fertility was improved by the application of fertilizer.

There have been many studies pertaining to salt-affected farmlands and rehabilitation (Agus and Tinning 2008; Nakaya et al. 2010). The drainage system, including the underground one, plays an important role in desalinization by both rainwater and irrigation water. In addition, in this study region, the ground along the coastal areas 


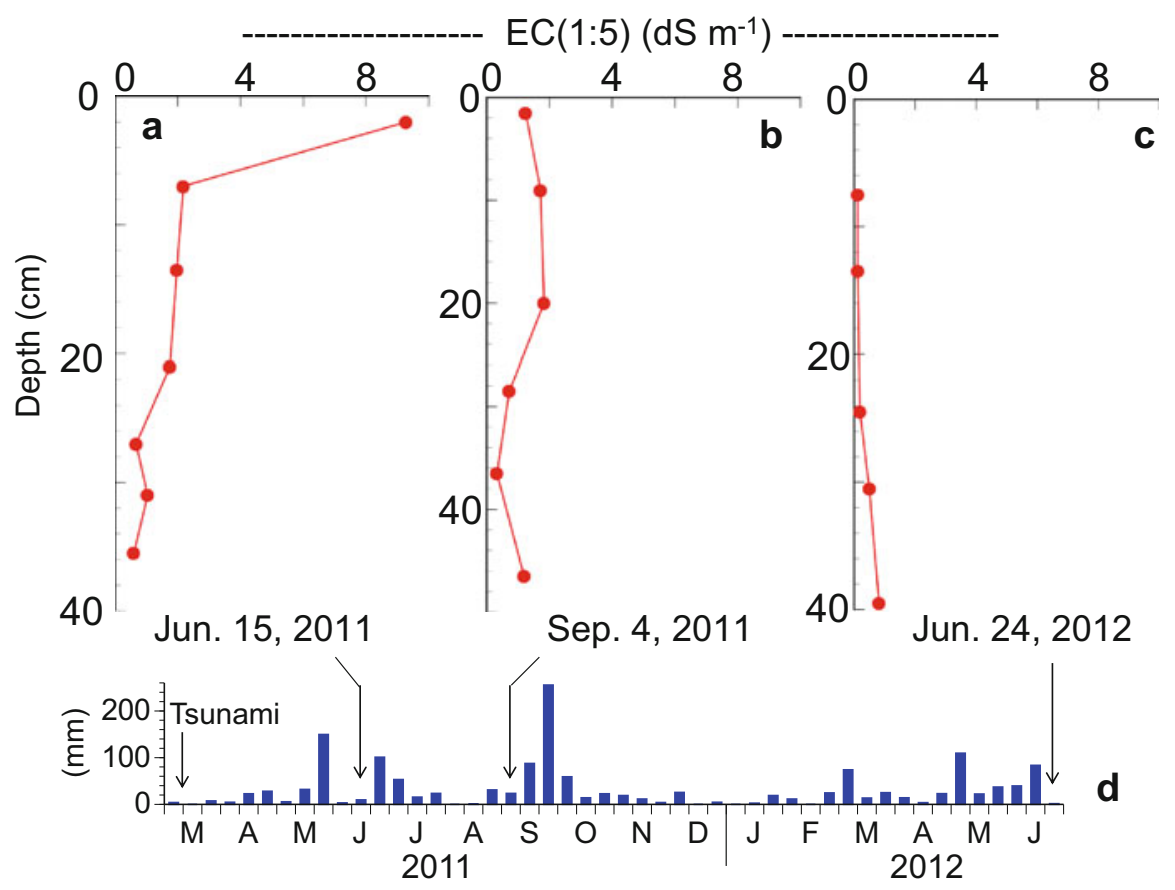

Fig. 6.14 Changes in the vertical distribution of EC(1:5) in the tsunami-affected paddy field soils under only natural rainwater. The uppermost tsunami deposit was removed artificially between September 4, 2011, and June 24, 2012. These three small pedons were sampled from two neighboring paddy fields. (a) June 15, 2011, (b) September 4, 2011, (c) June 24, 2012, (d) precipitation between March 2011 and June 2012. For an example of the soil profile of (a, b, and c), see Fig. 6.16a

sank by several tens of centimeters due to the earthquake. In these areas, dikes, drainage, and the pumping system should be restored.

Even when salt removal was successful in the upper part of the farmland soil, soluble salts partly remained in the lower part of the soil (Fig. 6.14c). In the case of the paddy fields, if irrigation water is supplied, the detrimental effect of the salt remaining in the subsoil may be negligible for rice growth because the salt may move further downward due to the percolation of the irrigation water. However, the salt remaining in the lower part of the soil may affect the growth of soybean, which is often cultivated in the drained rice fields due to rice production control. The salt tolerance of plants varies widely. During the survey in May 2011, barley had spikes in the tsunami-affected fields, although the plant height was short because spring fertilizer had not been applied.

By the spring of 2012,39\% of the damaged farmland had been restored (Ministry of Agriculture, Forestry and Fisheries, Japan 2012). In Fukushima Prefecture, restoration has been delayed due to contamination by radioactive materials from the nuclear power plant accident. 


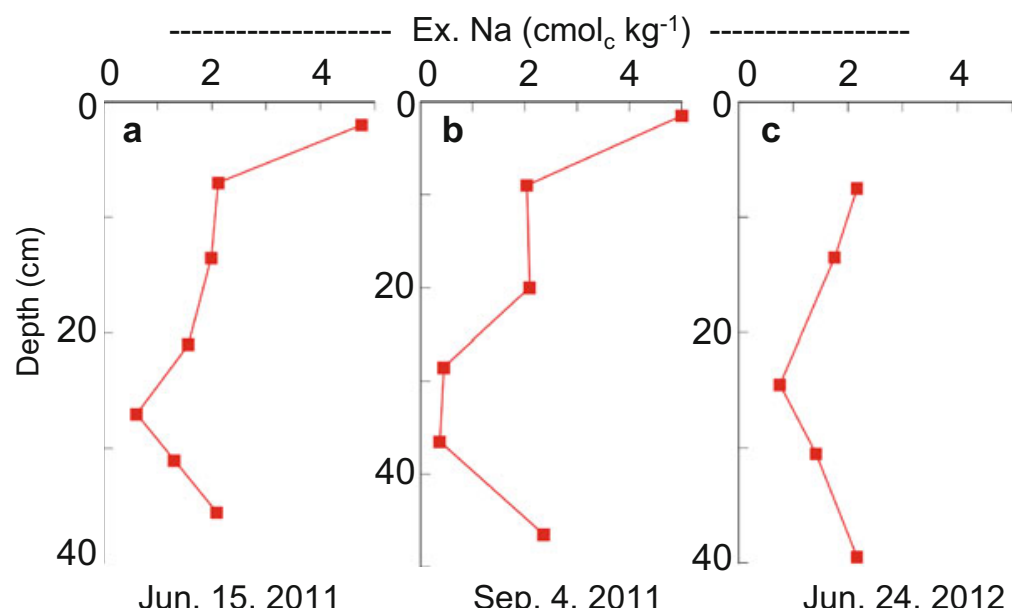

Fig. 6.15 Changes in the vertical distribution of exchangeable $\mathrm{Na}^{+}$with time in the same three pedons shown in Fig. 6.14. The uppermost tsunami deposit was removed artificially between September 4, 2011, and June 24, 2012

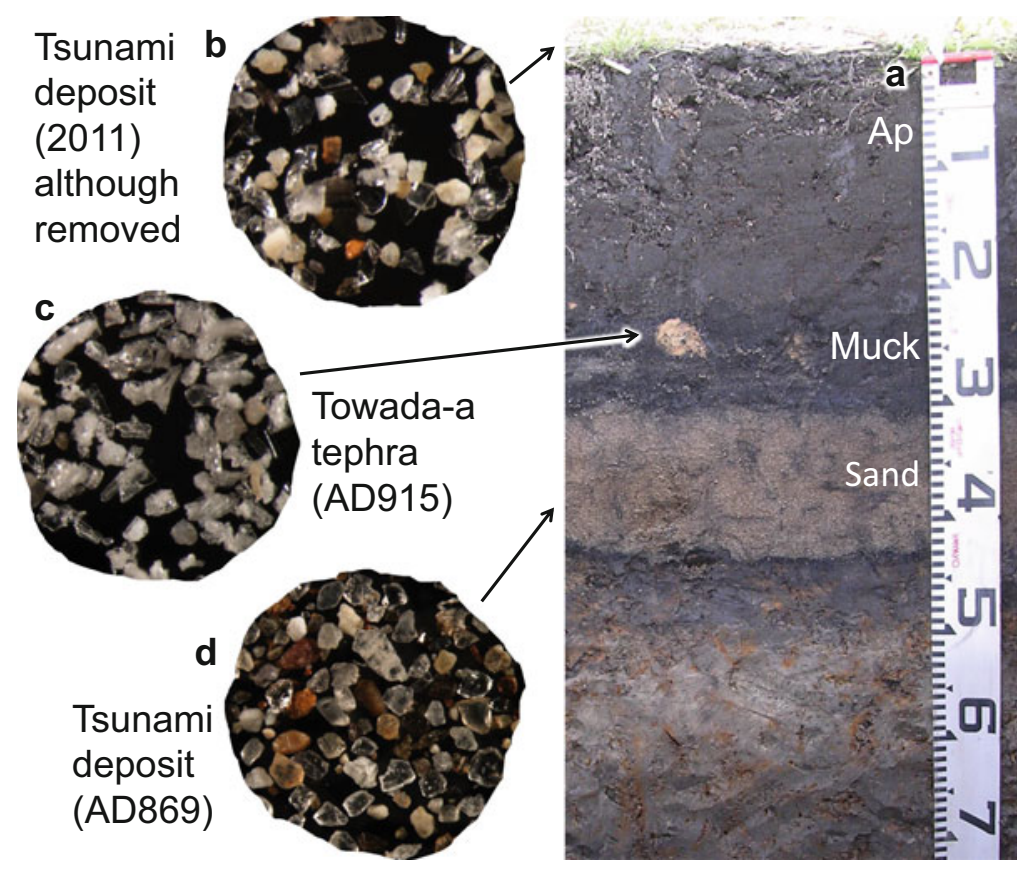

Fig. 6.16 Geological records of huge tsunamis. (a) Soil profile inundated by the 2011 tsunami, (b, c, and d) sand fractions of tsunami deposit (2011), Towada-a tephra (AD915), and tsunami deposit (AD869), respectively 
Huge tsunamis have been recorded in many places in the world (Okal 2011; Satake et al. 2011). The Indian Ocean tsunami of 2004 was a recent huge tsunami, such huge tsunamis have occurred repeatedly in the region in the past (Monecke et al. 2008). The evidence of previous tsunamis is recorded as relatively well-sorted sandy layers.

According to geological records (Minoura et al. 2001), the present study area has also been struck repeatedly by huge tsunamis. Figure 6.16a shows a soil profile including an old sandy tsunami deposit. Although the present tsunami deposits are removed in Fig. 6.16a, the sand fraction of the 2011 tsunami deposit is shown in Fig. 6.16b. At the depth of 20-30 cm from the surface, the Towada-a (To-a) tephra, an indicator of the soil age of AD 915, occurs as light-brown patches (Fig. 6.16a). The underlying sand layer is the tsunami deposit of AD 869 (Minoura et al. 2001). The sand fraction particles shown in Fig. 6.16b, d have similar subrounded shapes, which suggests sea sand. The ${ }^{14} \mathrm{C}$ age of plant fragments collected from the soil horizon beneath the tsunami deposit layer (AD 869) is consistently old (1450 BP) (Kanno et al. 2013).

\subsection{Radiocesium}

Radiocesium is a radioactive element that is an artificial contaminant of the soilbiota system. Although radiocesium is sorbed strongly by soil inorganic constituents, especially weathered mica (Fig. 2.21), a trace fraction of the radiocesium is absorbed by plants, fungi, and other organisms. The half-lives of ${ }^{134} \mathrm{Cs}$ and ${ }^{137} \mathrm{Cs}$ are 2.1 and 30.2 years, respectively.

Radiocesium was introduced into soils all over the world in the 1950s-60s due to atmospheric nuclear testing and it remains detectable in soil. Furthermore, radiocesium was released into the environment by the accidents at the nuclear power plants in Chernobyl (1986) and Fukushima (2011).

Although Steinhauser et al. (2014) estimated that the total release of radionuclides from the Fukushima Daiichi Nuclear Power Plant (FNPP) accident (approximately $520(340-800) \mathrm{PBq}$ ) was approximately one order of magnitude lower than the release from Chernobyl (approximately $5300 \mathrm{PBq}$ ), both accidents have been rated as "major accidents" by the International Atomic Energy Agency. This section describes the radiocesium contamination of soil from the FNPP accident, which was caused by the huge tsunami that occurred on March 11, 2011.

\subsubsection{Horizontal Distribution of Radiocesium}

Highly contaminated areas are distributed in an inverse L-shaped pattern in the northwestern direction from the FNPP (Fig. 6.17), although more than $80 \%$ of the entire radioactive elements was released to the Pacific Ocean. Factors related to the 


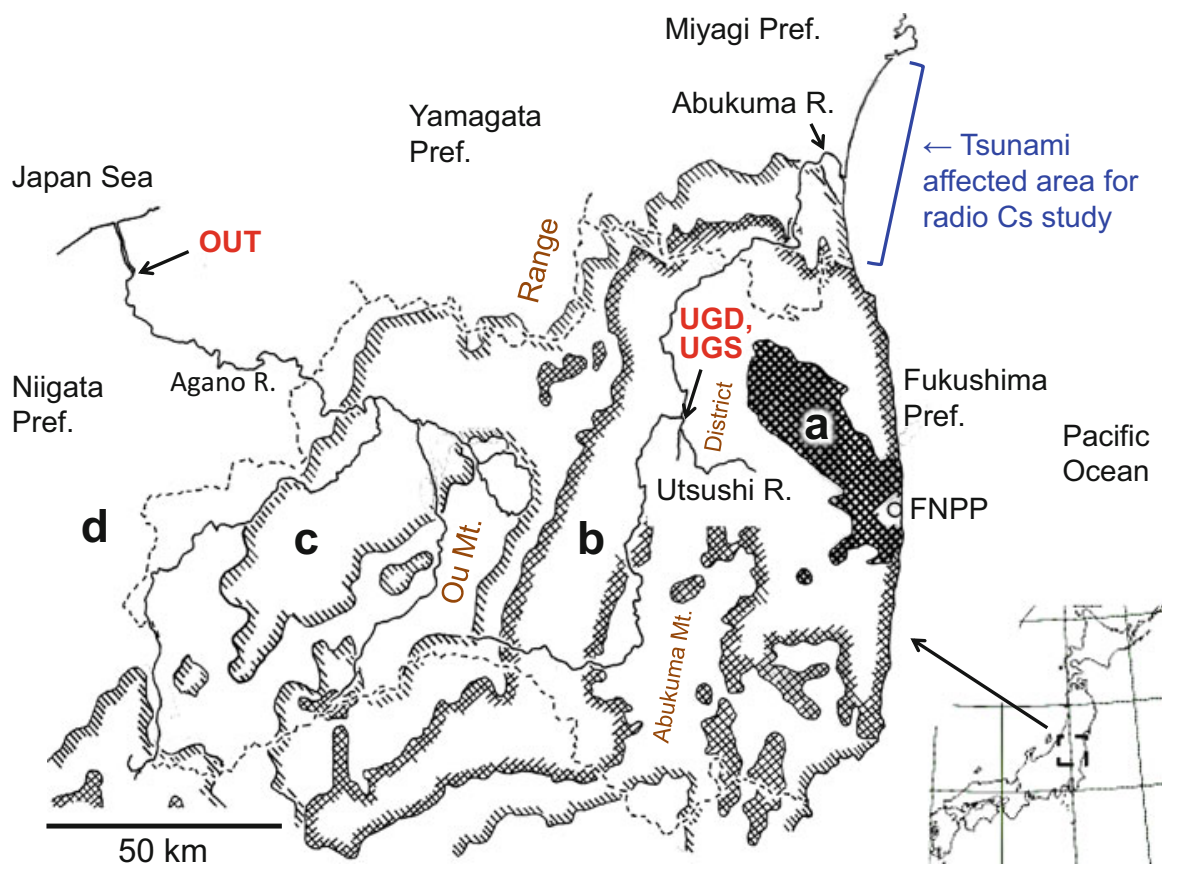

Fig. 6.17 Tracing of deposition densities of ${ }^{134} \mathrm{Cs}+{ }^{137} \mathrm{Cs}\left(\mathrm{Bq} \mathrm{m}^{-2}\right.$, a > $1000 \mathrm{k} ; 1000 \mathrm{k}>\mathrm{b}>60 \mathrm{k}$; $60 \mathrm{k}>\mathrm{c}>10 \mathrm{k} ; \mathrm{d} \leqq 10 \mathrm{k}$ ) made by using airborne monitoring results (converted as of October 13, 2011) of the Geospacial Information Authority of Japan (2014). UGD and UGS: sampling sites in the Utsushi River of Fukushima Prefecture, OUT: sampling site in the Agano River of Niigata Prefecture. Branches of Abukuma River and Agano River are not shown for simplicity, although they are numerous. FNPP: Fukushima Daiichi Nuclear Power Plant of the Tokyo Electric Power Co., Inc. The study site of radiocesium in the tsunami-affected area is shown in blue

radiocesium distribution are the wind direction to the northwest of the FNPP and the topography of the area (Hirose 2016; Saito et al. 2015). On March 15, 2011, a large amount of radioactive elements was released from the FNPP. The wind direction at that time was from the coastal area to the Abukuma Mountain District. When the wind reached the Ou Mountain Range, the wind was directed to a southern direction. As the weather in these areas was rainy or snowy on the day of the accident, radiocesium was deposited by wet scavenging (Saito et al. 2015).

\subsubsection{Vertical Distribution of Radiocesium in Soil}

Fixation of radiocesium is so strong that most of the radiocesium deposited on the surface of soil hardly moves and remains near the soil surface. The vertical distribution of radiocesium was determined in the tsunami-affected areas in Miyagi 


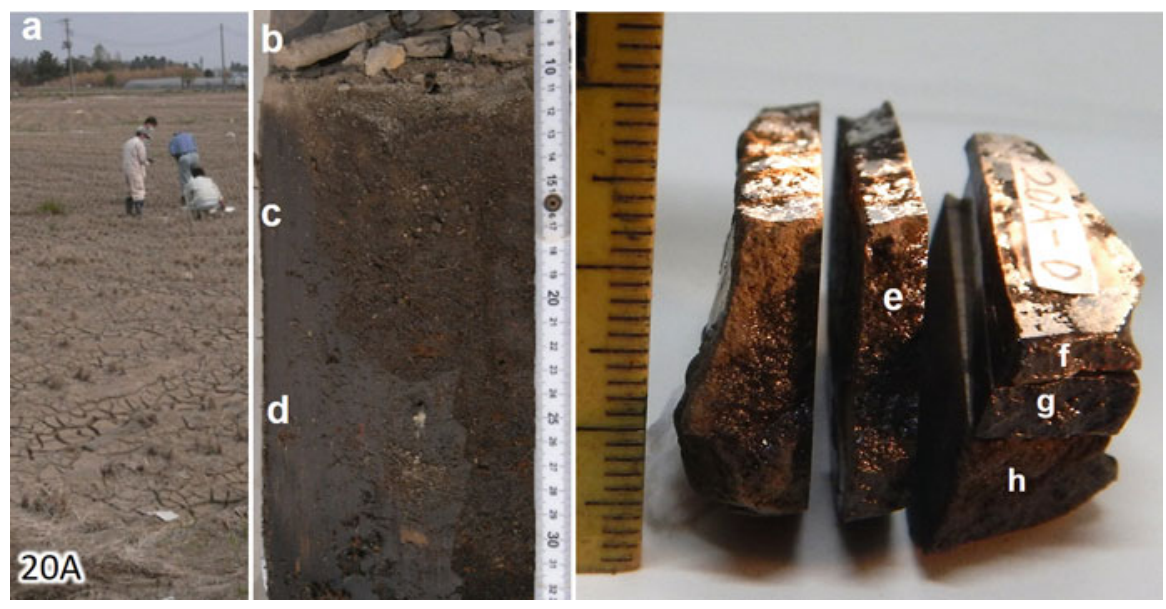

Fig. 6.18 An example sampling site for the radiocesium study. (a) Tsunami-affected farmland (sampling site No. 20A), (b) muddy tsunami deposit, (c) original soil 1, and (d) original soil 2 of this sampling site, (e) vertical section, (f, $\mathbf{g}$, and $\mathbf{h}$ ) horizontal sections (2-3 mm thick) of the muddy tsunami deposit (b)

Prefecture. The area is located between 50 and $100 \mathrm{~km}$ north of the FNPP (Fig. 6.17), and it is the same as in Fig. 6.4b. Although the tsunami deposits were mostly removed from the farmland in Miyagi Prefecture, the distribution of radiocesium in these soils may need to be taken into account in subsequent management of the soils. Figure 6.18a shows one of the sampling sites. The method used to collect samples of the tsunami deposits and the original soils was the same as that described in Sect. 6.2.1. Figure 6.18b, c, d show muddy tsunami deposit, original soil 1, and original soil 2, respectively. The muddy tsunami deposit (Fig. 6.18b) was cracked by desiccation at the time of sampling. The sandy tsunami deposit at this site was too thin to sample separately.

Fine-earth fractions from a total of 17 fields, seven from Sendai, five from Natori, and five from Watari-Yamamoto (open red circles in Fig. 6.19a), were packed into commercial U-8 plastic containers to the height of $12 \mathrm{~mm}$, and radiocesium activity concentrations were determined using gamma-ray spectrometry (see Sect. 1.4) (Nanzyo et al. 2015).

The muddy tsunami deposit had the highest radiocesium activity concentration at all 17 sites (Fig. 6.18b, c, d). Activity concentrations of radiocesium lower than those of the muddy tsunami deposit were also detected in the sandy layer at several sites. The radiocesium activity concentrations in the underlying original soils 1 and 2 were very low. These results show that the muddy tsunami deposits fixed most of the radiocesium deposited in this area. Thus, the distribution of radiocesium in the muddy tsunami deposit was examined further.

Soil sections were prepared by cutting vertical layers from a piece of cracked muddy tsunami deposit after hardening the piece with resin (Fig. 6.18e). The 


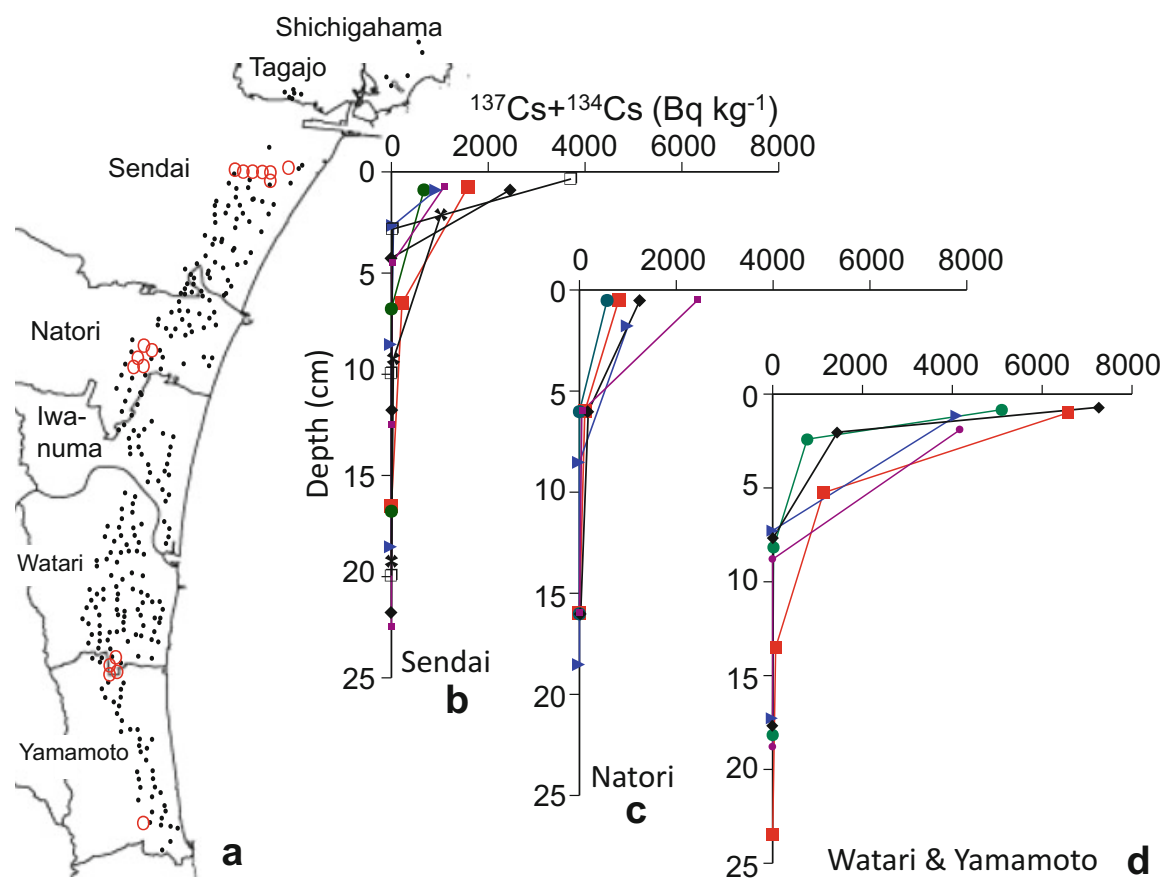

Fig. 6.19 Vertical distribution of radiocesium. (a) Map showing the 17 locations of tsunamiaffected soils used for the radio Cs study (red open circles), (b, $\mathbf{c}$, and $\mathbf{d}$ ) vertical distribution of radio Cs concentration in the Sendai, Natori, and Watari \& Yamamoto areas, respectively. The uppermost plot at each location show the radiocesium concentrations of the muddy tsunami deposit. The deepest and the second deepest plot at each location show the radiocesium concentrations of the original soil 2 , and 1 , respectively

sections were attached to one side of a strip of double-sided adhesive tape, attached to cardboard using the other side of the tape, and then covered by a thin plastic sheet. The cardboard was placed on an imaging plate (IP) for 30 days to detect radioactivity (see Sect. 1.4).

The IP results of the vertical sections revealed two distribution patterns of radioactivity (Fig. 6.20). One pattern was a line of spots with high radioactivity near the surface of the muddy layer. The radioactivity of these spots was sufficiently high to indicate that the radioactivity was from radiocesium. The distribution of these spots suggests that a significant fraction of the radiocesium had been deposited as particulate material (Adachi et al. 2013) and that deposition of the radioactive particulate material occurred after the sedimentation of the muddy tsunami deposit. The other pattern was a very faint, layer distribution at the upper part of the vertical section. If this radioactivity was also from radiocesium, the radiocesium may have been deposited in a soluble form and become fixed by suspended soil materials in the inundation water during sedimentation (Mukai et al. 2016). It was not clear whether a few spots showing radioactivity at the side edge of " $2 \mathrm{~A}$ " from Watari \& 


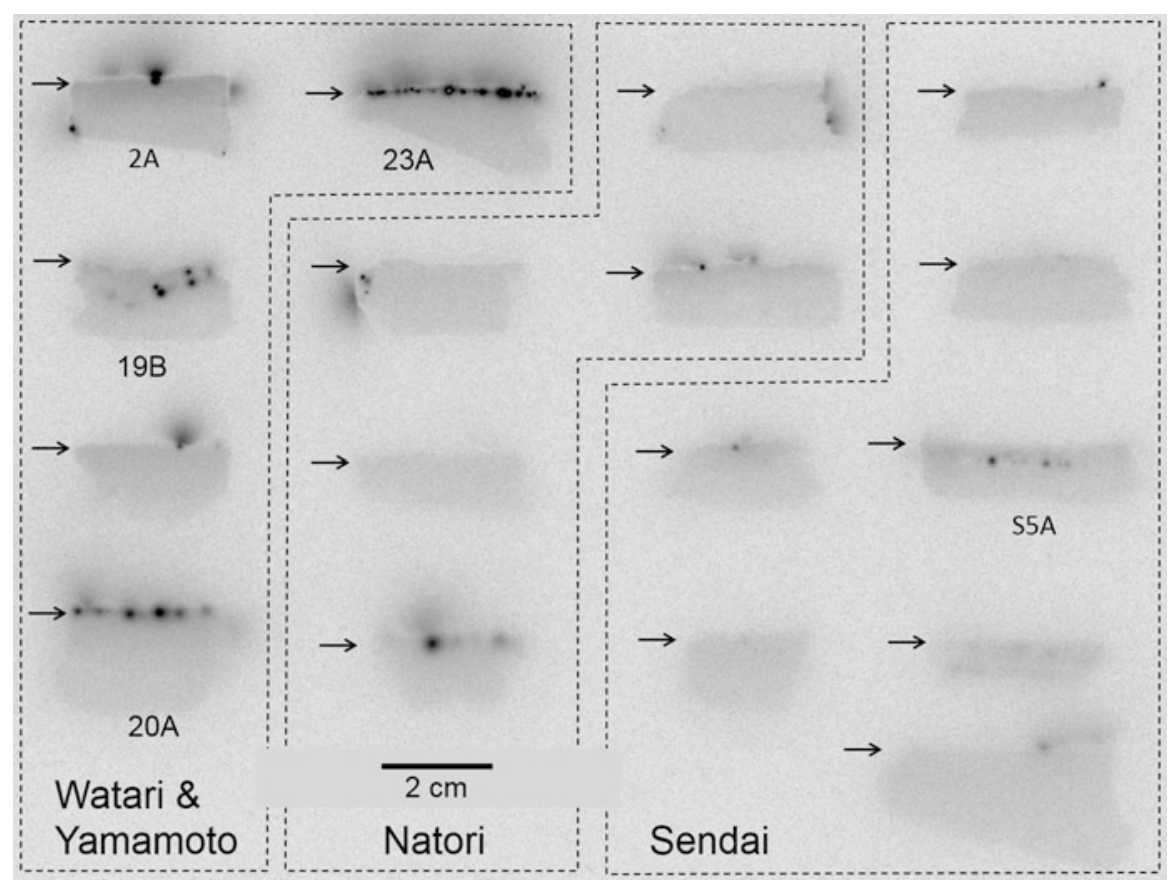

Fig. 6.20 Distribution of radioactivity determined by an imaging plate using vertical sections of muddy tsunami deposits from the Sendai, Natori, and Watari \& Yamamoto areas. See Fig. 6.18e for information about the samples used. Arrows show the positions of the surface of the muddy tsunami deposits

Yamamoto, for example, were a type of artifact formed during handling of the sample or were from some other cause.

Because the radioactivity of spots of samples $20 \mathrm{~A}$ and $23 \mathrm{~A}$ was so intensive, the vertical distribution of radioactivity was examined using 2-3 $\mathrm{mm}$ thick horizontal sections of four samples (2A, 23A, 20A, and S5A), as exemplified in Fig. 6.18f, g, h. The same gamma-ray spectrometry used for Fig. 6.19 was used for radiocesium measurement of the horizontal sections. The results are shown in Fig. 6.21. As shown by the many radioactive spots in "20A" and "23A" in Fig. 6.20, higher radioactivity concentration was obtained from the surface sections (Fig. 6.21), suggesting high radioactivity of the spots near the surface of the sections. In the cases of " $2 \mathrm{~A}$ " and "S5A", as there were fewer radioactive spots, the radioactivity concentrations of the surface sections were not as distinctively high as those of "20A" and "23A". The radiocesium concentration of the second layer of " $2 \mathrm{~A}$ " appears higher than that of the third section, suggesting that the faint layer distribution of radioactivity of " $2 \mathrm{~A}$ " in Fig. 6.20 is due to radiocesium.

Using "19B" and "20A" of the muddy tsunami deposits shown in Fig. 6.20, six particle size fractions were prepared after $\mathrm{H}_{2} \mathrm{O}_{2}$ digestion followed by wet sieving and a sedimentation method. The radiocesium concentrations of the six particle size 
Fig. 6.21 Vertical distribution of radiocesium concentration in the muddy tsunami deposit. For the sample preparation, see Fig. 6.18f, g, h
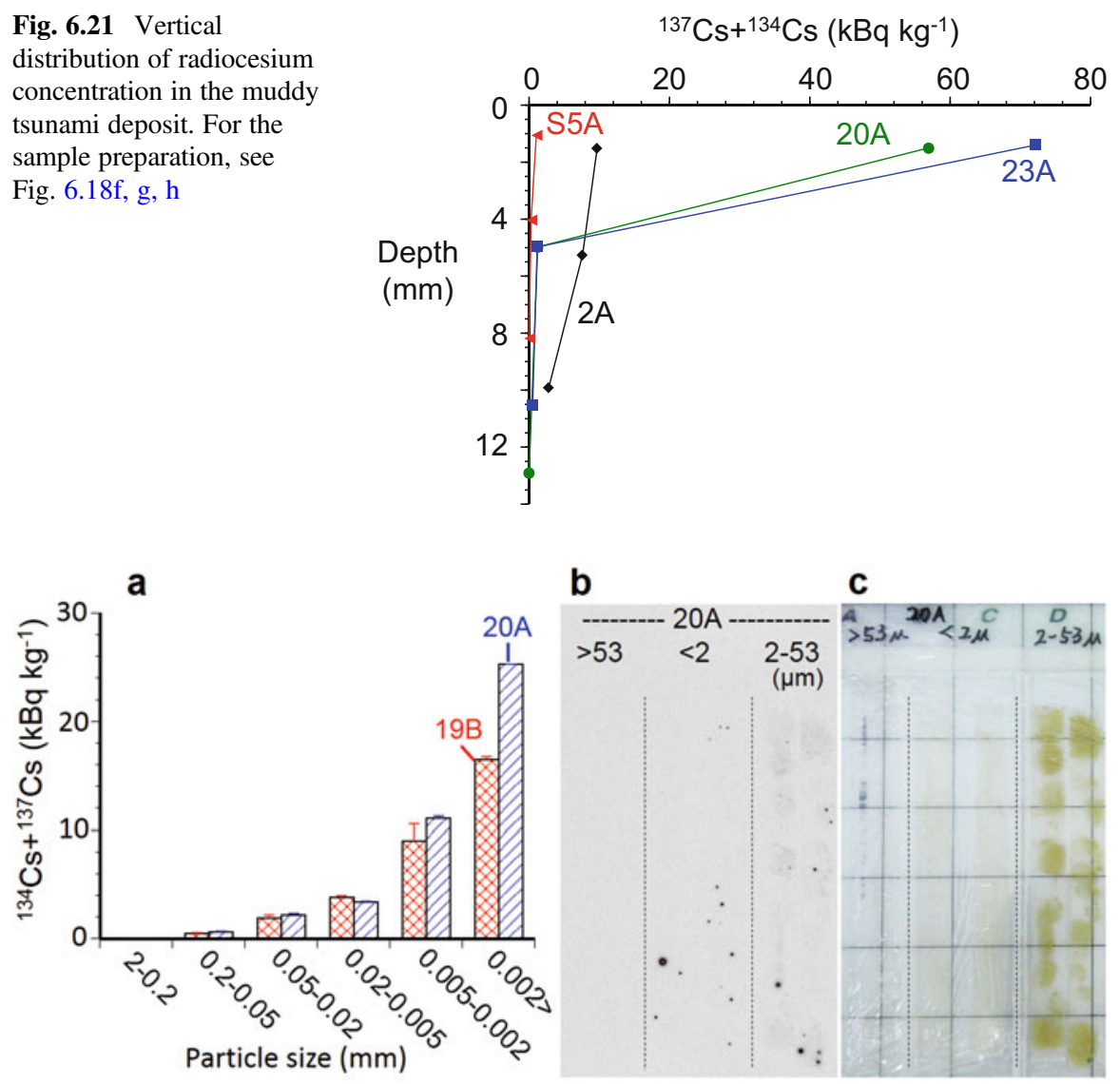

Fig. 6.22 Radiocesium in the muddy tsunami deposits. (a) Changes in radiocesium concentrations with particle size, (b) radioactivity of three particle size fractions using an imaging plate (IP), (c) optical photograph of the three particle size fractions used for radioactivity detection using IP. Samples 19B and 20A are the same as those in Fig. 6.20

fractions obtained using the same method as in Fig. 6.19 are shown in Fig. 6.22a. Among the six particle size fractions, the radiocesium concentration was highest in the clay fraction $(<2 \mu \mathrm{m})$, and it decreased with increasing particle size. The radioactivity of the three particle size fractions shown in Fig. 6.22c was also detected using the same IP method used for Fig. 6.20. In the two particle size fractions of $<2 \mu \mathrm{m}$ and $2-53 \mu \mathrm{m}$, high radioactivity particles were significantly detected, whereas few were detected in the $>53 \mu \mathrm{m}$ particle size fraction. Hence, the highly radioactive particles in "20A" are smaller than $53 \mu \mathrm{m}$ in diameter. The highly radioactive particles appeared to be stable during $\mathrm{H}_{2} \mathrm{O}_{2}$ treatment and particle size fractionation, but they disappeared when the $<2 \mu \mathrm{m}$ fraction was treated with hot $6 \mathrm{~mol} \mathrm{~L}^{-1} \mathrm{KOH}$.

Radioactivity was also detected in the particle size fractions larger than $53 \mu \mathrm{m}$ (Fig. 6.22a). Weathered biotite grains larger than $53 \mu \mathrm{m}$ may be included in the muddy tsunami deposit because they can fix radiocesium. 


\subsubsection{Fixation of Cesium Ion by Soil}

The mechanism of radiocesium fixation by weathered biotite is similar to that for potassium, which is shown in Fig. 3.11. Although a large amount of cesium was added, the fixed cesium can be detected by EDX. Figure 6.23a shows examples of partially weathered biotite particles. The particles still include potassium. After washing the weathered biotite particles twice with $2 \mathrm{~mol} \mathrm{~L}^{-1} \mathrm{CsCl}$ solution, followed by washing with water, and air-drying, X-ray counts from $\operatorname{Cs}(\operatorname{L} \alpha)$ are detectable in the EDX spectrum (Fig. 6.23b). The $\operatorname{Cs}(\operatorname{L} \alpha)$ peak is not detected in the EDX spectrum of the untreated sample (Fig. 6.23c). The fixed Cs is also detectable in a Cs element map (Fig. 6.23d). Cs is distributed over the whole area of the weathered biotite particles, where $\mathrm{K}$ is also detected (Fig. 6.23e). Under the accelerating voltage of $15 \mathrm{kV}$, X-rays from the depth of about $1 \mu \mathrm{m}$, which is much thicker than the basal spacing $(1 \mathrm{~nm})$ of biotite, are detected (see Sect. 1.4).
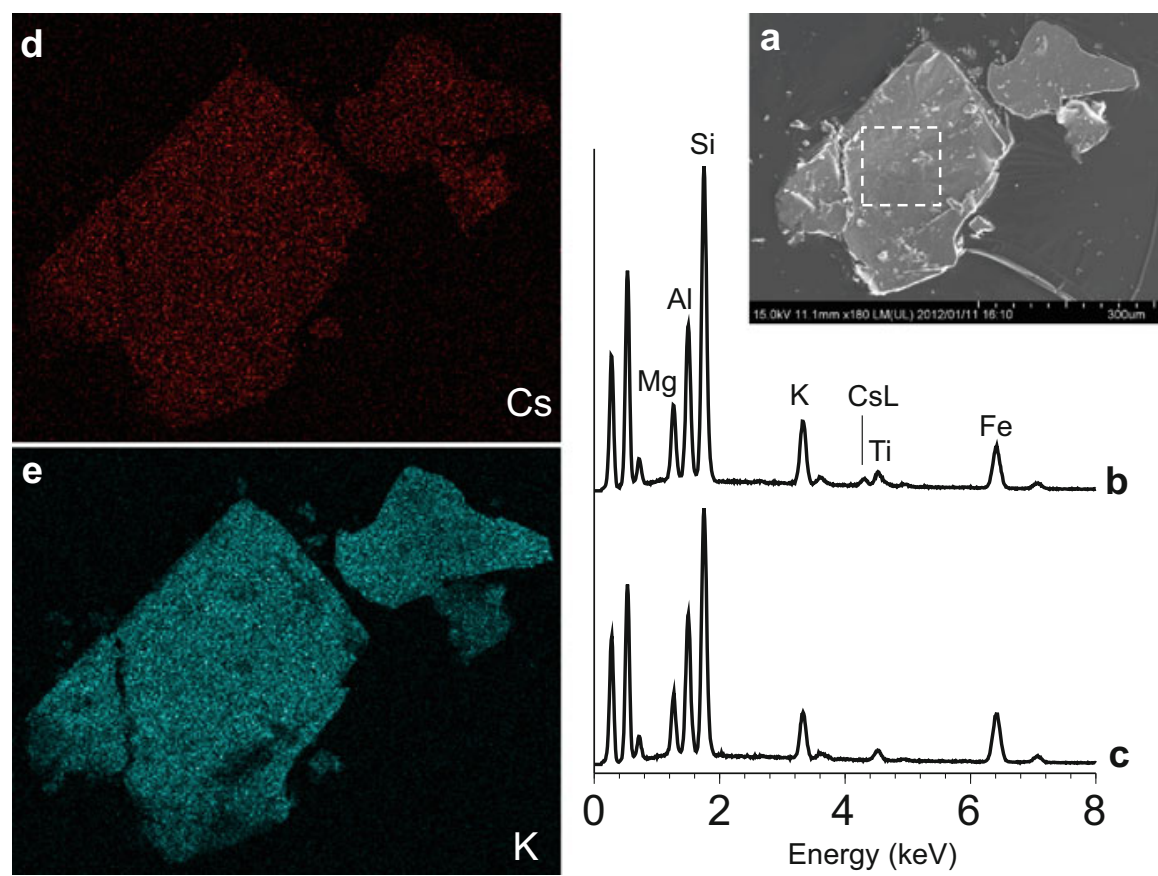

Fig. 6.23 Fixation of cesium ion by weathered biotite. (a) SEM image of weathered biotite particles picked up from a side bar deposit (2nd layer, Fig. 6.25a) of the Utsushi River, (b and c) EDX spectra of Cs-sorbed and untreated weathered biotite, respectively, (d and e) element maps of Cs and K, respectively, of the Cs sorbed weathered biotite particles. The EDX spectrum (b) was obtained from the dashed square in (a) 


\subsubsection{Transportation of Radiocesium in Rivers Estimated from Side Bar Deposits}

The radiocesium deposited on a soil surface is fixed by soil particles (Shiozawa 2013; Nakao et al. 2014). However, when the soil particles move because of erosion, the radiocesium moves with the particles. High radiocesium concentration was detected in the water treatment residue (WTR) (Ippolito et al. 2011) from the Aganogawa water purification plant which locate near Ounbashi sampling site (OUT) in Fig. 6.17, $170 \mathrm{~km}$ away from FNPP. In the case of rivers, soil particles move with the water in suspended form, particularly during heavy rains (Evrard et al. 2014), and are eventually deposited as bars. Bars are often found in slow-flowing, shallow parts of a river.

The Fukushima nuclear accident in 2011 was followed by snowmelt, heavy rain, and a typhoon, which caused rising levels of muddy water in rivers and the formation of bars. Information about the transportation and deposition of soil particles with radiocesium may be obtained from these side bars.

Contrasting vertical distributions of radiocesium from soil can be found in the river side bar deposits. On December 24, 2011, there were side bar deposits with a depth of 1-2 m on the right side of the Utsushi-Gawa dam (UGD) (Fig. 6.24a). Soil samples collected from the dam lakeshore (Fig. 6.24b) (UGS), which is located on the right side of the UGD, showed an ordinary vertical distribution pattern of radiocesium: the surface soil had high radiocesium concentration and the radiocesium concentration decreased steeply with increase of depth (Fig. 6.24c).

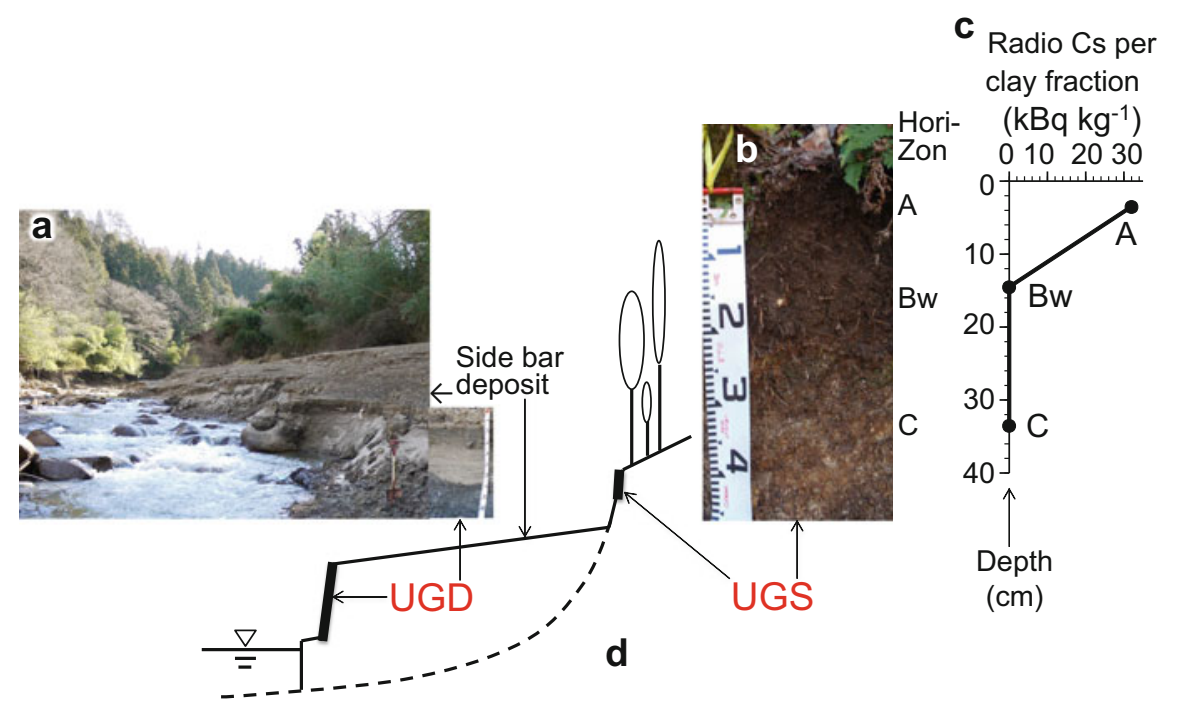

Fig. 6.24 Contrasting vertical distribution of radiocesium between soil and side bar deposit. (a) Landscape and profile of side bar deposit at the Utsushi-Gawa dam (UGD), (b) soil profile of the Utsushi-Gawa dam lakeshore (UGS), (c) vertical distribution of radiocesium concentration per clay fraction of UGS, (d) schematic diagram showing the relationship between UGD and UGS 


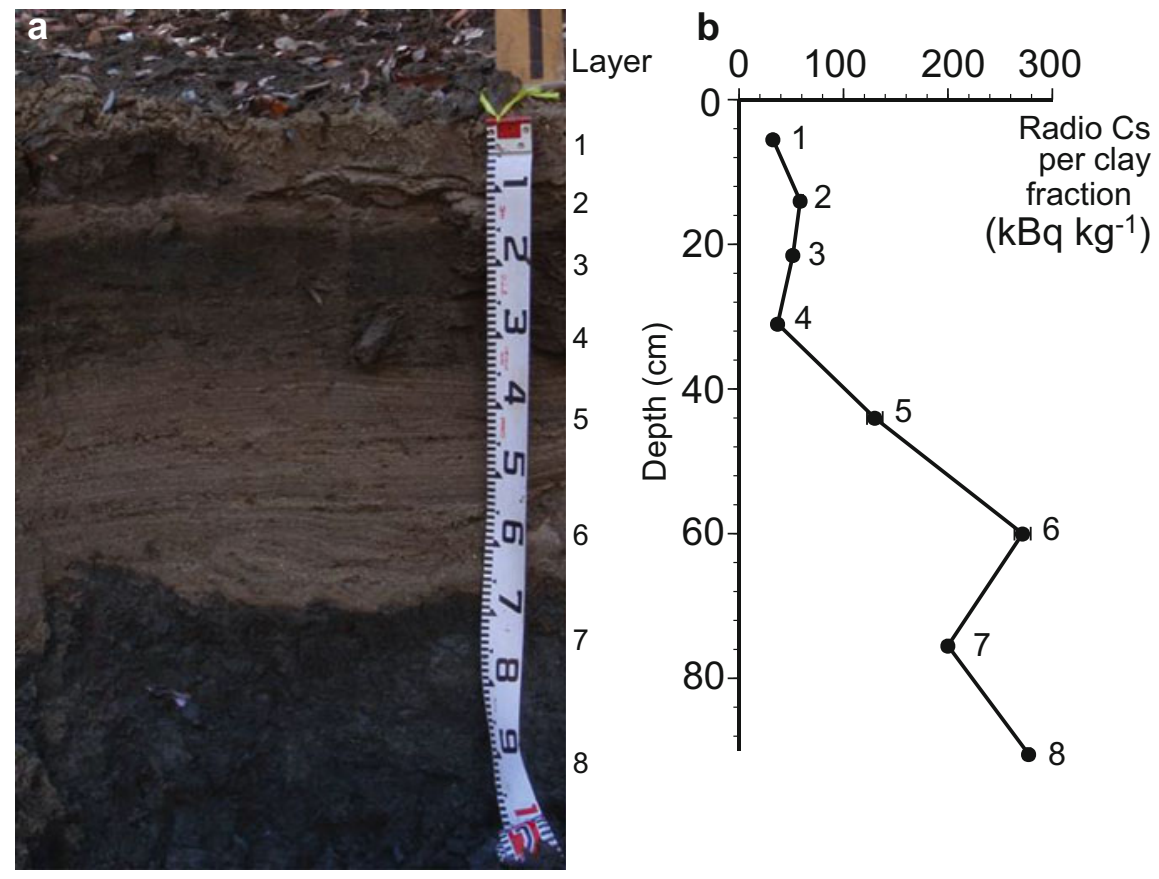

Fig. 6.25 Radiocesium in the side bar deposit. (a) Profile of the side bar deposit of the UtsushiGawa Dam (UGD), (b) vertical distribution of radiocesium concentration per clay fraction of the side bar deposit

High concentrations of radiocesium were detected especially from the 8th layer of the UGD site (UGD-8) (Fig. 6.25b) as the Utsushi River flows from the Abukuma Mountain District close to the FNPP (Fig. 6.17). The radiocesium concentration differed widely among layers. UGD-5 and UGD-6 were artificially subdivided layers with a similar appearance in the field, yet with a fine cumulative stratification (Fig. 6.25a). Layers UGD-7 and UGD-8 were similarly separated. The vertical distribution of the clay content also differs widely. High clay content appears to coincide with high radiocesium concentration, suggesting that clay minerals are the most important binder of radiocesium. In addition, the radiocesium concentration decreased upward, with lower radiocesium concentrations in UGD-1 than in UGD-7, despite almost identical clay content (Nanzyo et al. 2014).

The side bar deposits (UGD of Fig. 6.25 and OUT of Fig. 6.26) were thick and included layers with various clay content. Although some sand-sized vermiculite can carry radiocesium, clay minerals that receive fallout of radiocesium play a major role in carrying radiocesium (Tsukada et al. 2008). However, the sand content of the side bar deposit is changeable depending on the velocity of water flow, and the clay content may be diluted with sand. The concentration of radiocesium per clay fraction should more directly reflect the effect of fallout, especially in the sandy layers of the side bar deposits. Furthermore, the radiocesium concentration per clay fraction can 


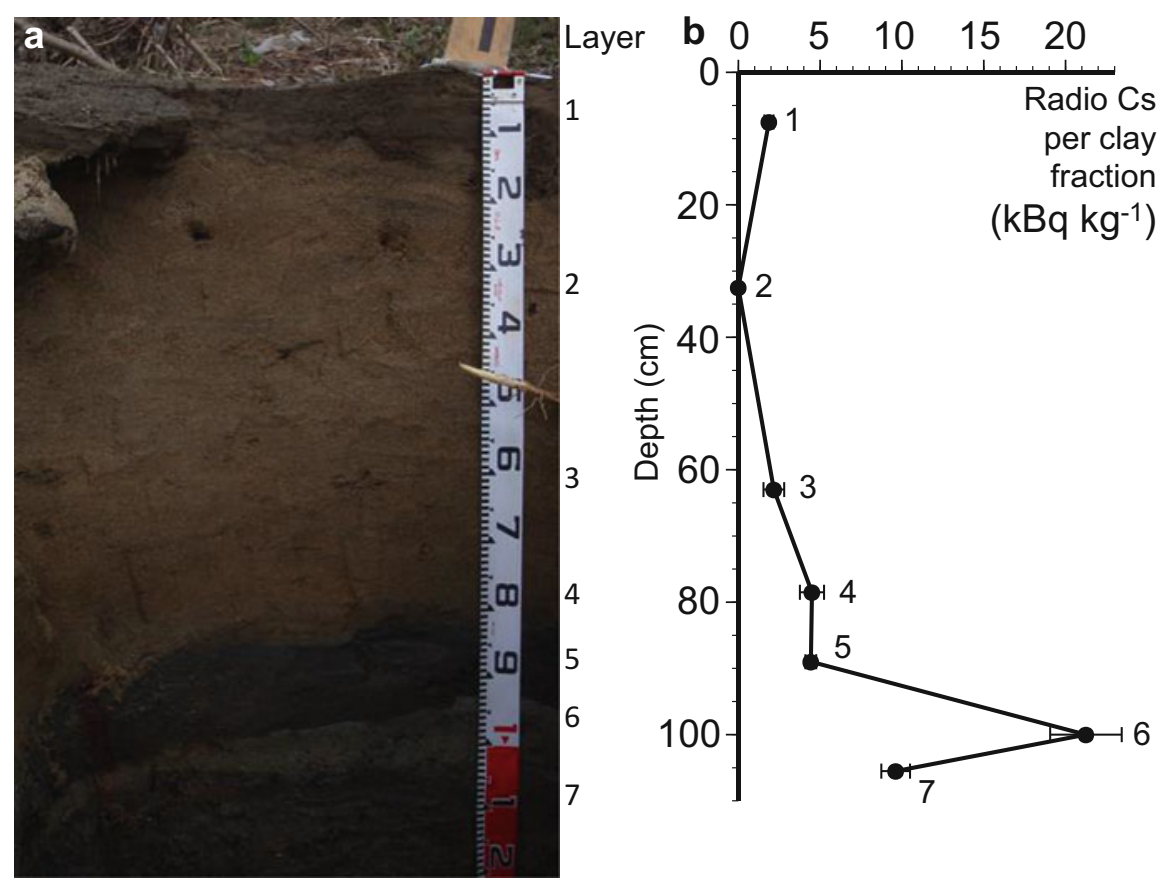

Fig. 6.26 Radiocesium in side bar deposit. (a) Profile of the side bar deposit of the Ounbashi Aganogawa (OUT), (b) vertical distribution of radiocesium concentration per clay fraction of the side bar deposit

be more comparable to that of the WTR from a water purification plant, considering their particle size. Hence, the concentration of radiocesium per clay fraction was calculated by dividing the concentration of radiocesium in each layer by the clay content of the layer. The results are shown in Figs. 6.25b and 6.26b. The radiocesium per clay fraction was more than five times greater than that in the fine earth fraction (particle diameter $\leqq 2 \mathrm{~mm}$ ). For UGD, the concentration of radiocesium in the clay fraction was high in the earlier (lower) muddy layers, UGD-7 and UGD-8. High concentrations of radiocesium per clay fraction continued into the sandy UGD-6 layer, after which the concentrations decreased (Fig. 6.25b).

Similar results were obtained for OUT, as shown in Fig. 6.26; however, the maximum concentration of radiocesium per clay fraction (OUT-6, ca. $20 \mathrm{kBq} \mathrm{kg}^{-1}$ ) was an order of magnitude smaller than that of UGD.

The maximum concentration of radiocesium per clay fraction of OUT (Fig. 6.26b) was similar to that of the WTR from the Aganogawa water purification plant, 35,400 Bq kg${ }^{-1}$, sampled during August 24-30, 2011 (Yomiuri Newspaper 2011). This WTR was generated by the water purification treatment during the period of December 2010-May 2011. If the particle size of the WTR generated from the water purification plant is comparable to the size of the clay fraction, it would justify the similarity of these values. The radiocesium per clay fraction of OUT decreased in the shallow layers that were deposited later. Similarly, the 


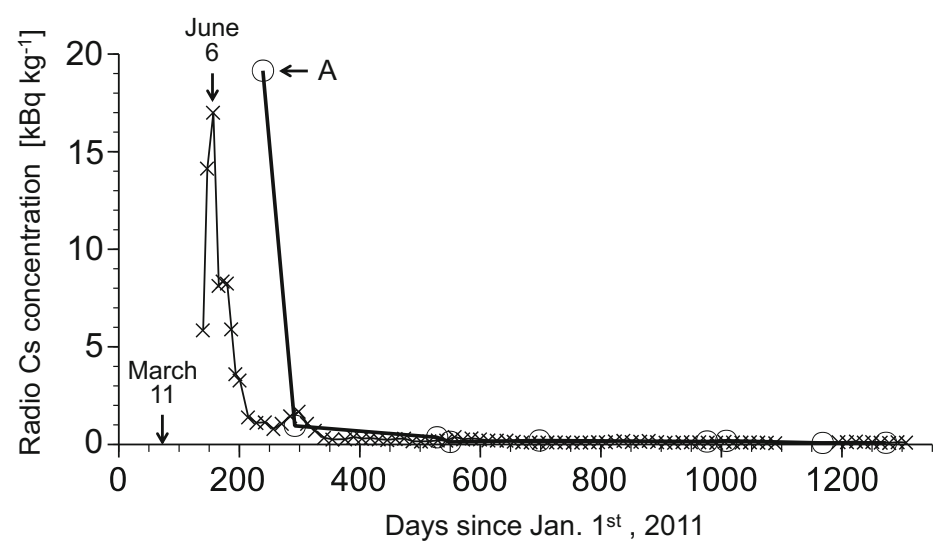

Fig. 6.27 Changes in radiocesium concentration of water treatment residue from the Aganogawa $(O)$ and Manganji $(\times)$ water purification plants with days since January 1, 2011 (DSJF). The plots shown by $(O)$ are midpoints calculated from maximum and minimum values. For instance, plot $A$ is the midpoint between 2890 and $35,400 \mathrm{~Bq} \mathrm{~kg}^{-1}$ observed during 236 and $242 \mathrm{DSJF}$. The DSJF of the water intake from the Agano River was 45-60 days and 120-240 days earlier than the measurement of radiocesium at the Manganji and Aganogawa water purification plants, respectively

concentration of radiocesium in the WTR decreased steeply, although values of hundreds of $\mathrm{Bq} \mathrm{kg}{ }^{-1}$ lasted for several months, according to the Aganogawa (Niigata City 2014) and Manganji water purification plant report (Niigata City 2014b), as shown in Fig. 6.27. Many data are available from the Manganji water purification plant where WTR is produced by machine dewatering every 1.5-2 months. The frequency of WTR production is less at the Aganogawa water purification plant where WTR is produced by sun-drying every several months. Results similar to those of Fig. 6.27 were reported from water purification plants in Saitama Prefecture (Saitama Prefecture 2014).

Radiocesium may have deposited on riverbeds with little water or alternatively on the snow of riverbeds and riverside areas. Hence, the high radiocesium concentration in WTR and in the lower layers of the relatively new side bar deposits at UGD and OUT may be related to snowmelt-related transport of soil particles or water containing radiocesium (Nanzyo et al. 2014).

Further readings are Nakanishi and Tanoi $(2013,2016)$.

\subsection{Phosphates Related to Soil-Plant Systems}

The phosphorus concentration of Earth's crust is estimated to be $0.1 \%$. Phosphorus is one of the major essential elements of the organisms, and it is one of the elements that limit the amount of biota. In farmlands, phosphate (P) fertilizer is effective for increasing crop production. However, as soils more or less fix P, the efficiency of $\mathrm{P}$ 
fertilizer is generally lower than those of nitrogen and potassium fertilizers. Thus, increasing the efficiency of $\mathrm{P}$ fertilizers, typically lower than $20 \%$, is a concern. $\mathrm{P}$ accumulates in the plow layer soils of farmlands, and with an increase in $\mathrm{P}$ accumulation, a portion of the $\mathrm{P}$ is released gradually to rivers, lakes, and bays causing eutrophication. The natural resource of $\mathrm{P}$ fertilizers is phosphate rock. Economically mineable phosphate rock appears to be limited (Amundson et al. 2015), although estimates of the world P reserves require further research (Edixhoven et al. 2014). As $70-80 \%$ of phosphate rock is consumed as fertilizers, a sustainable management method of $\mathrm{P}$ or recycling of $\mathrm{P}$ is desirable for farmlands. This section introduces the forms of $\mathrm{P}$ related to soil-plant systems, except for those discussed in Chap. 5.

\subsubsection{Apatite and Related Reactions}

Apatite is a major mineral of phosphate rock. The general chemical formula of apatite is $\mathrm{Ca}_{5}\left(\mathrm{PO}_{4}\right)_{3} \mathrm{X}\left(\mathrm{X}=\mathrm{F}^{-}, \mathrm{Cl}^{-}, \mathrm{OH}^{-}\right.$, and others $)$. Apatite is largely divided into apatite of sedimentary and igneous origins. Apatite of sedimentary origin is microcrystalline, whereas apatite of igneous origin is highly crystalline.

Figure 6.28 shows an example of a sedimentary-origin apatite from Florida, USA. As shown in the optical micrograph (Fig. 6.28a), the major particles are subrounded and have various sizes, although some are broken. The particles have mostly grayish color, but some are light-brown or some other color. These particles are apatite, except for a small amount of colorless transparent quartz. As shown in the magnified SEM image (Fig. 6.28b), the sedimentary apatite appears to be an aggregate of microcrystals. According to the EDX spectrum (Fig. 6.28c), the Florida apatite has a significant amount of $\mathrm{F}^{-}$. The powder XRD pattern (Fig. 6.28d) is identical to the pattern of the reference fluoroapatite (Fig. 6.28e), except that a small amount quartz is included.

Apatite is converted to fine powder or to more soluble $\mathrm{P}$ fertilizers, such as $\mathrm{Ca}$ $\left(\mathrm{H}_{2} \mathrm{PO}_{4}\right)_{2} \cdot \mathrm{H}_{2} \mathrm{O},\left(\mathrm{NH}_{4}\right)_{2} \mathrm{HPO}_{4}$, and others, by adding acids.

Fresh apatite particles are found in young volcanic ash soils (Fig. 6.29) (Nanzyo et al. 1997; Nanzyo and Yamasaki 1998; Nanzyo et al. 2003) or granitic soils (Fig. 2.18). These have an igneous origin and are more crystalline than those of sedimentary origin. As apatite is a minor constituent in volcanic ash and has high particle density, heavy liquid is used to concentrate apatite particles. An example of volcanic ash, from Mt. Pinatubo (1991), is shown in Fig. 6.29 (Nanzyo et al. 1997). An SEM image of the heavy fraction of the Pinatubo ash is shown in Fig. 6.29a, and four P-rich particles were identified using element maps. The particle labeled " $b$ " and one other particle are almost entirely composed of apatite because their shapes in the element maps of P (Fig. 6.29d) and Ca (Fig. 6.29e) are very close to those in the SEM image (Fig. 6.29a). The particle labeled "c" is a composite particle with a FeTi oxide (Fig. 2.15), as shown in Fig. 6.30. The EDX spectra (Fig. 6.29b, c) of the dashed squares labeled "b" and "c" in Fig. 6.29a support the conclusion that these grains are apatite. 

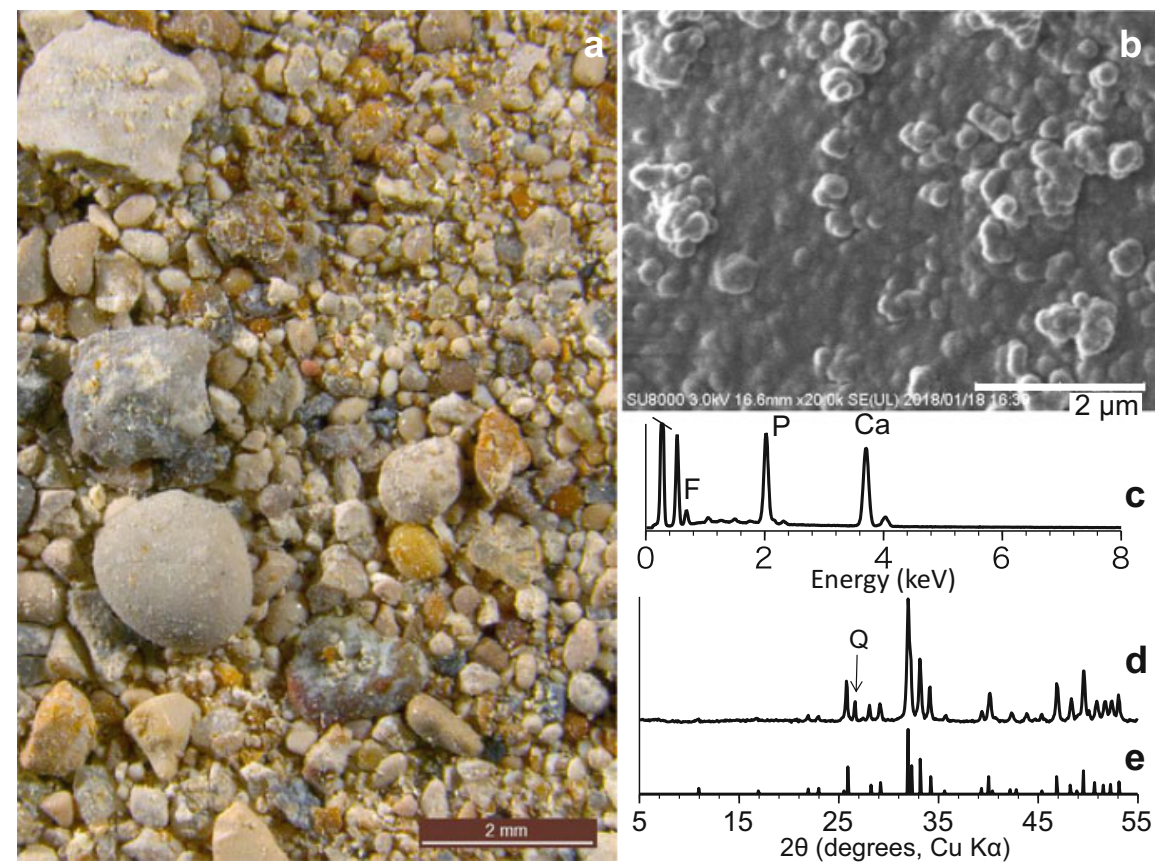

Fig. 6.28 Apatite from Florida, USA. (a) Optical micrograph, (b) SEM image, (c) EDX spectrum, (d) powder XRD pattern, (e) reference powder XRD pattern. (Lehr et al. 1967)

Acid solutions are used for the evaluation of plant-available $\mathrm{P}$ in soil. For example, in the Truog method, a solution containing $1 \mathrm{mmol} \mathrm{L}^{-1} \mathrm{H}_{2} \mathrm{SO}_{4}$ and $3 \mathrm{~g} \mathrm{~L}^{-1}$ of ammonium sulfate is used to extract $\mathrm{P}$ from soil. Although apatite is not highly available for many crop plants, apatite is soluble in the Truog extracting solution (Fig. 6.30). Figure 6.30a shows a magnified composite particle of apatite and a Ti-Fe mineral. After obtaining the SEM image (Fig. 6.30a), the sample was treated with the Truog extracting solution, and a part of apatite apparently dissolved (Fig. 6.30b). The thin transparent film around the dissolved apatite particle in Fig. 6.30b corresponds to vacuum-evaporated carbon. Although the apatite particle was dissolved significantly by this treatment, the chemical composition of the remaining part represented by a dashed square of Fig. 6.30d in Fig. $6.30 \mathrm{~b}$ was still the same as before the treatment (Fig. 6.29c). The Fe-Ti oxide in contact with the apatite was not affected by this treatment.

The Truog P levels of tephra depend on the rock type (Fig. 6.30e). The fresh rhyolitic to andesitic tephra showed Truog P levels higher than $100 \mathrm{mg} \mathrm{P}_{2} \mathrm{O}_{5} \mathrm{~kg}^{-1}$, whereas the basaltic and basaltic-andesitic tephra showed only low Truog $\mathrm{P}$ values. These results are consistent with those obtained by Green and Watson (1982), who reported that apatite or $\mathrm{P}_{2} \mathrm{O}_{5}$ solubility in silicate melts increases with decreasing $\mathrm{SiO}_{2}$ content and that crystallization of apatite cannot occur in mafic and low-P 

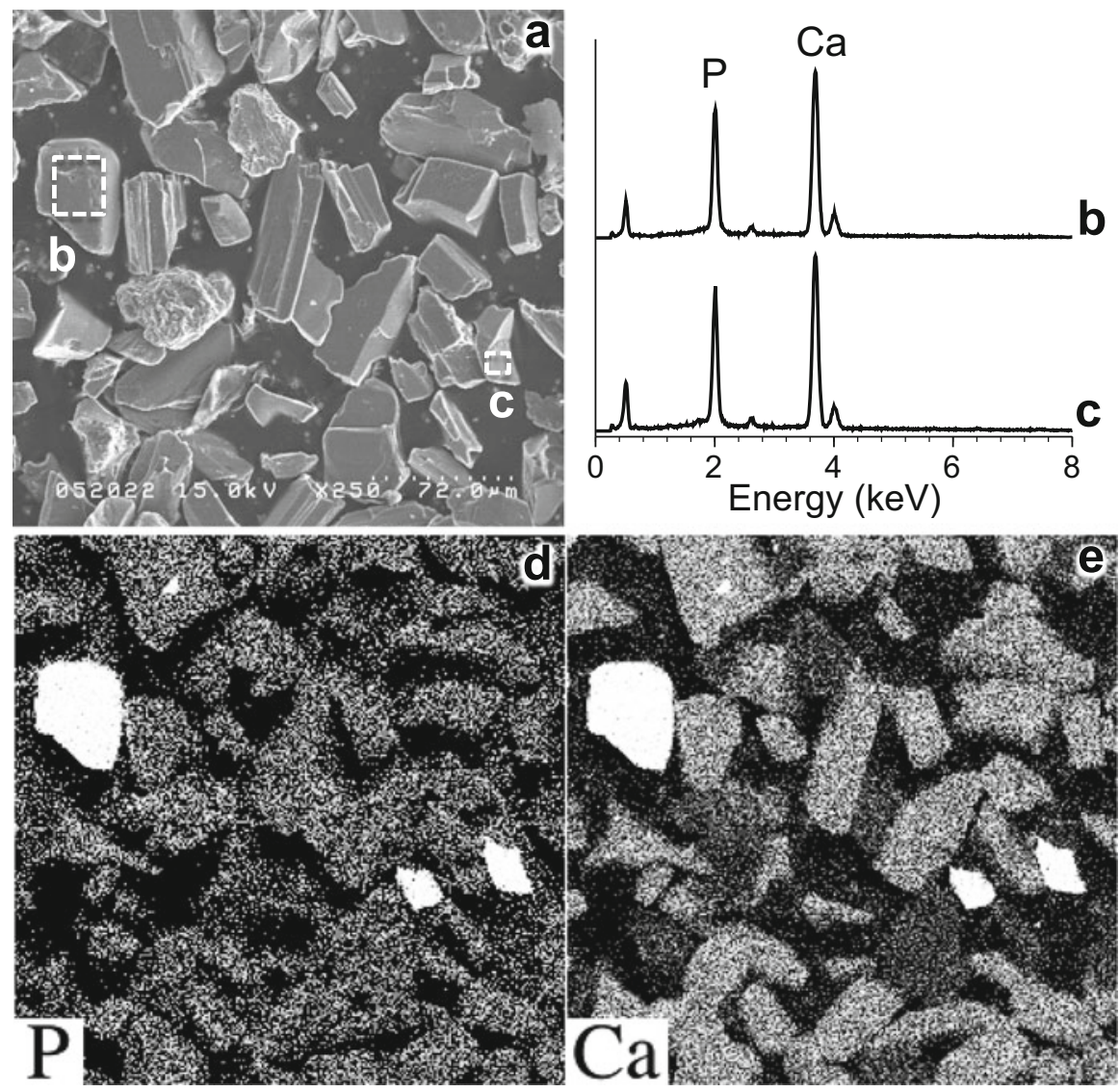

Fig. 6.29 Apatite particles in the Mt. Pinatubo volcanic ash (1991). (a) SEM image of the fraction with particle size less than $0.05 \mathrm{~mm}$ and specific gravity greater than $2.8 \mathrm{Mg} \mathrm{m}^{-3}$, (b and c) EDX spectra of the dashed squares (b) and (c) in (a), (d and e) element maps for $\mathrm{P}$ and $\mathrm{Ca}$, respectively

magmas with less than about $2 \mathrm{~g} \mathrm{P}_{2} \mathrm{O}_{5} \mathrm{~kg}^{-1}$. On the other hand, apatite crystallizes over a larger $\mathrm{SiO}_{2}$ range in magmas with a higher $\mathrm{P}$ content than this level (Green and Watson 1982). As the total $\mathrm{P}$ content of the basaltic andesite and basaltic tephras used in the present study was $2.8 \mathrm{~g} \mathrm{P}_{2} \mathrm{O}_{5} \mathrm{~kg}^{-1}$ or less, crystallization of apatite could not occur and $\mathrm{P}$ was considered to be distributed to other minerals.

Dissolution of apatite is dependent on pH (Fig. 6.31d). Two apatite samples of sedimentary origin (Florida and Makatea) were treated with $10 \mathrm{mmol} \mathrm{L}^{-1}$ of citrate or dilute $\mathrm{HCl}$. The amount of $\mathrm{P}$ dissolved from the two apatite samples increased with decreasing final $\mathrm{pH}$ values and was larger in the citrate treatment than in the dilute $\mathrm{HCl}$ treatment, especially in the $\mathrm{pH}$ range of 5-6. This is possibly due to chelation of $\mathrm{Ca}$ and donation of $\mathrm{H}^{+}$by citrate. 

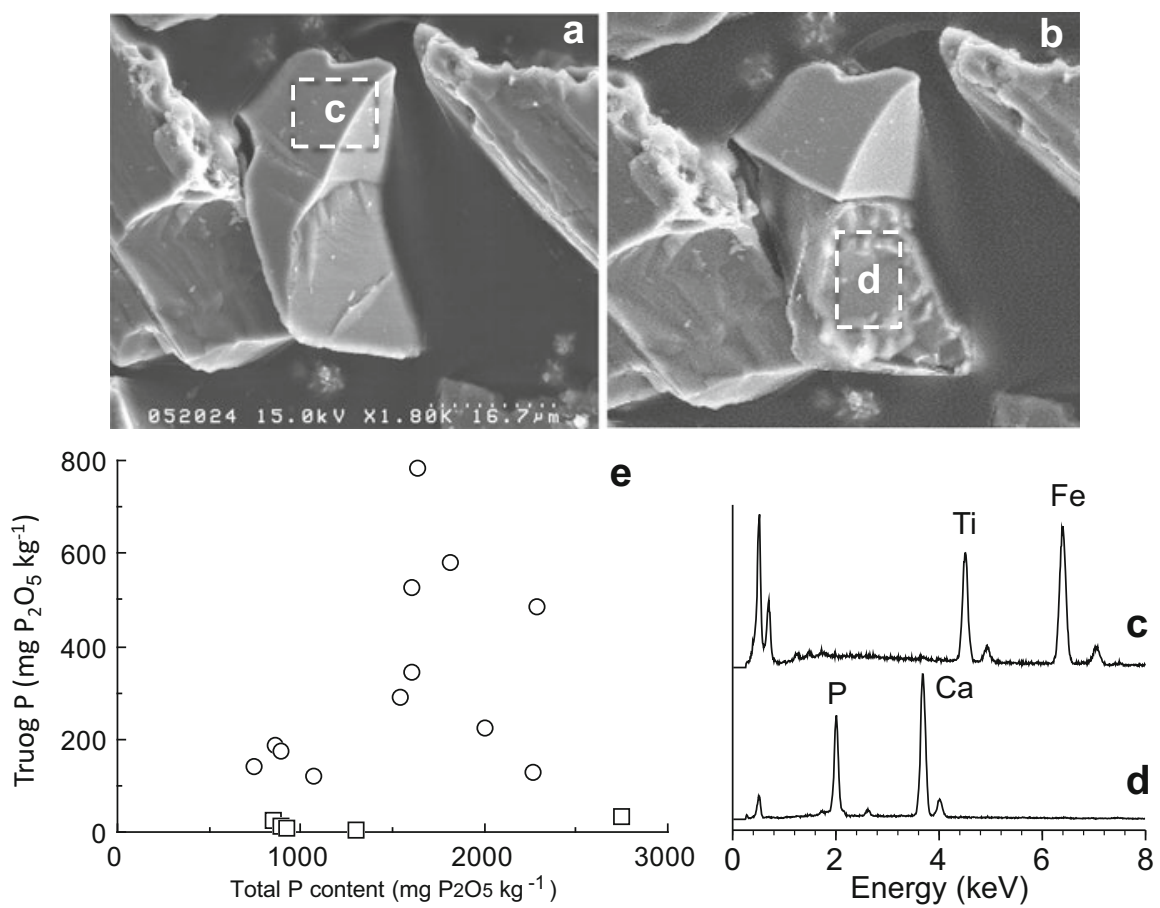

Fig. 6.30 Dissolution of apatite in the Truog extracting solution. (a) Magnified SEM image of particles included Fig. 6.29c, (b) SEM image after the treatment with Truog solution, (c and d) EDX spectra of the dashed areas (c) and (d) of Fig. 6.30a, b, respectively, (e) relationship between total P content and Truog P of rhyolitic to andesitic (open circles) and basaltic-andesitic to basaltic (open squares) tephras

In contrast, when the two apatite samples were treated with $10 \mathrm{mmol} \mathrm{L}^{-1}$ oxalate, the amount of $\mathrm{P}$ dissolved was much smaller than those of the treatment with citrate or $\mathrm{HCl}$ in the final $\mathrm{pH}$ range between 3.4 and 4.3 (Fig. 6.31d). When the final $\mathrm{pH}$ was about 3 with the treatment by citrate or dilute $\mathrm{HCl}$, the amount of $\mathrm{P}$ dissolved was more than $96 \%$ of the original $\mathrm{P}$ content of the samples. When the final $\mathrm{pH}$ was 3.4 with the treatment by oxalate, the amount of $\mathrm{P}$ dissolved was only about $10 \%$ of the original $\mathrm{P}$ content and was not much different from those at final $\mathrm{pH}$ of 6-7. The low $\mathrm{P}$ dissolution with oxalate treatment, compared with the dissolution of citrate or $\mathrm{HCl}$ treatment, was close to the result using the Pinatubo tephra containing apatite of igneous origin. The formation of a Ca oxalate coating on the surface of apatite from the oxalate treatment of the Florida apatite was revealed by XRD (Nanzyo et al. 1999). Similar results were also obtained for the Makatea apatite.

The distribution of the $\mathrm{Ca}$ oxalate by the oxalate treatment of the apatite samples was elucidated by SEM-EDX analysis. Figure 6.31a shows an SEM image of the surface (right-hand side) and the section (left-hand side) of an oxalate-treated Florida apatite particle at $\mathrm{pH} 4$. According to the selected area analysis, the peak intensity for $\mathrm{P}-\mathrm{K} \alpha$ of the surface of the particle (dashed square (b) in Fig. 6.31a) was much 


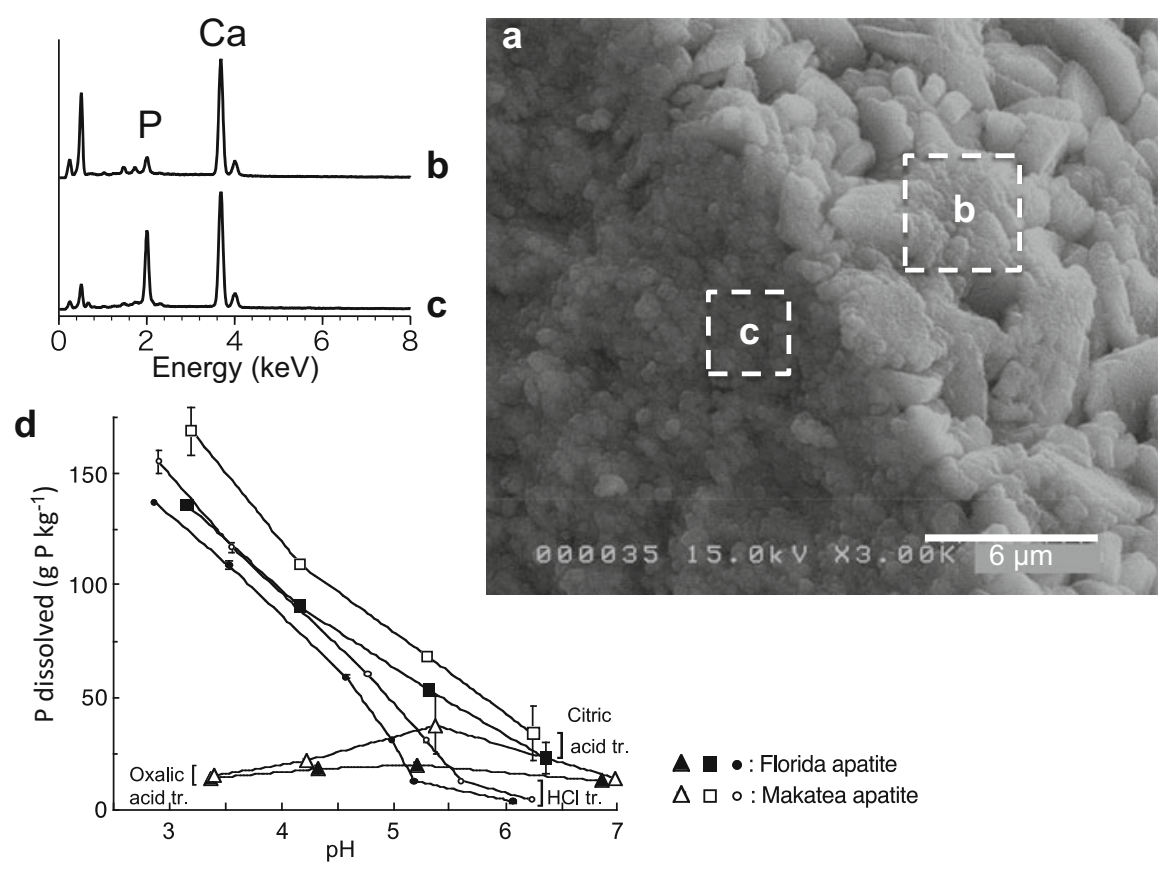

Fig. 6.31 Formation of Ca oxalate coating on an apatite particle. (a) SEM image of surface (b) and cross section (c) of Florida apatite treated with oxalate ( $\mathrm{pH} 4)$, (b and c) EDX spectra of dashed squares (b) and (c) of Fig. 6.31a, (d) changes in $\mathrm{P}$ dissolution with $\mathrm{pH}$ when treated with oxalate, citrate, and $\mathrm{HCl}$

weaker than that of the section (dashed square (c) in Fig. 6.31a). The thickness of the Ca oxalate coating was estimated to be less than $2 \mu \mathrm{m}$ based on the results from the line scan for $\mathrm{P}$. Thus, it was confirmed that $\mathrm{Ca}$ oxalate was formed as a surface coating material by oxalate treatment of the apatites and that the Ca oxalate coating inhibited further dissolution of apatite (Nanzyo et al. 1999).

Chickpea roots secrete organic acids (Ohwaki and Hirata 1992). A decrease in $\mathrm{pH}$ value and an increase in $\mathrm{P}$ concentration was detectable when chickpea was cultivated in the Pinatubo volcanic ash with a solution containing no P (Nakamaru et al. 2000).

As shown in Figs. 6.29 and 6.30, significant amounts of $\mathrm{P}$ are contained in fresh tephra, and the major P-bearing mineral in the andesitic to rhyolitic tephra is apatite. During the process of Andisol formation, apatite is dissolved gradually and the dissolved $\mathrm{P}$ is sorbed by active $\mathrm{Al}$ and Fe. Figure 6.32a shows an allophanic Andisol profile at Yunodai, Aomori Prefecture, Japan. The $\mathrm{C}$ horizon has $0.14 \%$ of oxalateextractable $\mathrm{Al}\left(\mathrm{Al}_{\mathrm{o}}\right)$ and $1.7 \%$ of oxalate-extractable $\mathrm{Fe}\left(\mathrm{Fe}_{\mathrm{o}}\right)$, indicating that it weakly weathered. Figure 6.32b shows an SEM image of weathered apatite (in and around the dashed square Fig. 6.32c) and allophanic material (in and around the dashed square Fig. 6.32d), determined from EDX spectra (c) and (d), respectively, in 


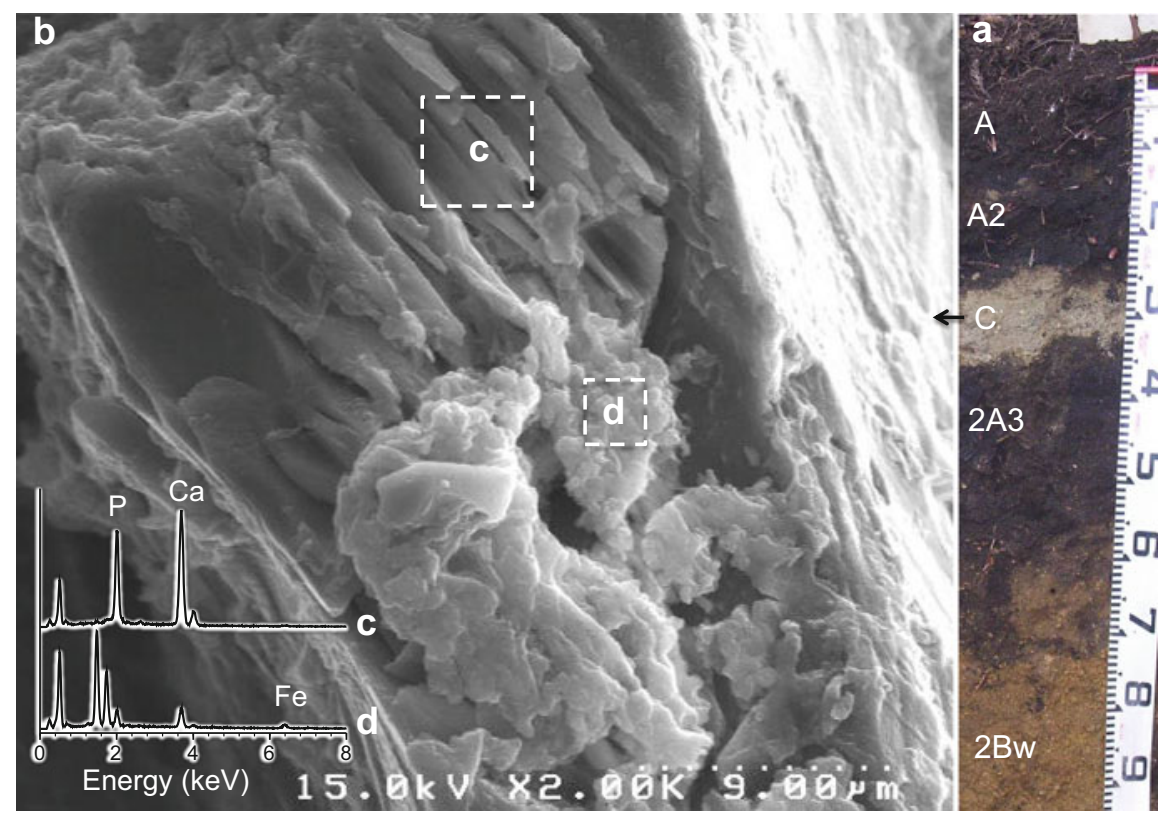

Fig. 6.32 Weathering of apatite in an Andisol. (a) Soil profile of Hapludand, (b) SEM image of a sand particle including partially weathered apatite and allophanic material, (c and d) EDX spectra of the dashed areas (c) and (d), respectively

Fig. 6.32b. Parallel-oriented thin prismatic form is a commonly found character of weathered apatite in a young Andisol. As the EDX spectrum Fig. 6.32c lacks X-ray counts for $\mathrm{Al}$ and $\mathrm{Fe}$, there is no coating of active $\mathrm{Al}$ or Fe materials on the surface of the weathered apatite, suggesting that weathering of apatite in and around the dashed square (c) is congruent dissolution of apatite. The reaction of apatite and active $\mathrm{Al}$ is different from the formation of a $\mathrm{Ca}$ oxalate coating on the surface of apatite (Fig. 6.31).

\subsubsection{Reactions of Phosphate with Active Al and Fe Materials}

Phosphate concentration in soil water is generally low, and it is less than $10^{-6} \mathrm{~mol} \mathrm{~L}^{-1}$ in mature Andisols, which are rich in active $\mathrm{Al}$ materials. This low $\mathrm{P}$ concentration in soil water is less than that at dissolution equilibrium of $\mathrm{AlPO}_{4} \cdot 2 \mathrm{H}_{2} \mathrm{O}$, variscite. The reason for the low $\mathrm{P}$ concentration in the soil water is that $\mathrm{P}$ is sorbed by active $\mathrm{Al}$ and $\mathrm{Fe}$. In general, $\mathrm{P}$ sorption by active $\mathrm{Al}$ and $\mathrm{Fe}$ occurs at lower $\mathrm{P}$ concentration than precipitation of $\mathrm{AlPO}_{4} \cdot 2 \mathrm{H}_{2} \mathrm{O}$ from soil water. With increase in the amount of $\mathrm{P}$ sorption, $\mathrm{P}$ concentration in soil water and the amount of plant-available $\mathrm{P}$ increase gradually. 
Fig. 6.33 Changes in infrared absorption spectra of phosphate and sulfate with sorption by aluminum hydroxide gel. (a) $\mathrm{NaH}_{2} \mathrm{PO}_{4}$ in water, (b) sorbed $\mathrm{H}_{2} \mathrm{PO}_{4}{ }^{-}$ at room temperature and atmospheric pressure, (c) sorbed $\mathrm{H}_{2} \mathrm{PO}_{4}{ }^{-}$at room temperature and reduced pressure, (d) sorbed $\mathrm{H}_{2} \mathrm{PO}_{4}{ }^{-}$ under reduced pressure at $373 \mathrm{~K}$, (e) $\mathrm{Na}_{2} \mathrm{SO}_{4}$ in water, (f) sorbed $\mathrm{SO}_{4}{ }^{2-}$ at room temperature and atmospheric pressure, (g) sorbed $\mathrm{SO}_{4}{ }^{2-}$ at room temperature and reduced pressure, (h) sorbed $\mathrm{SO}_{4}{ }^{2-}$ under reduced pressure at $373 \mathrm{~K}$

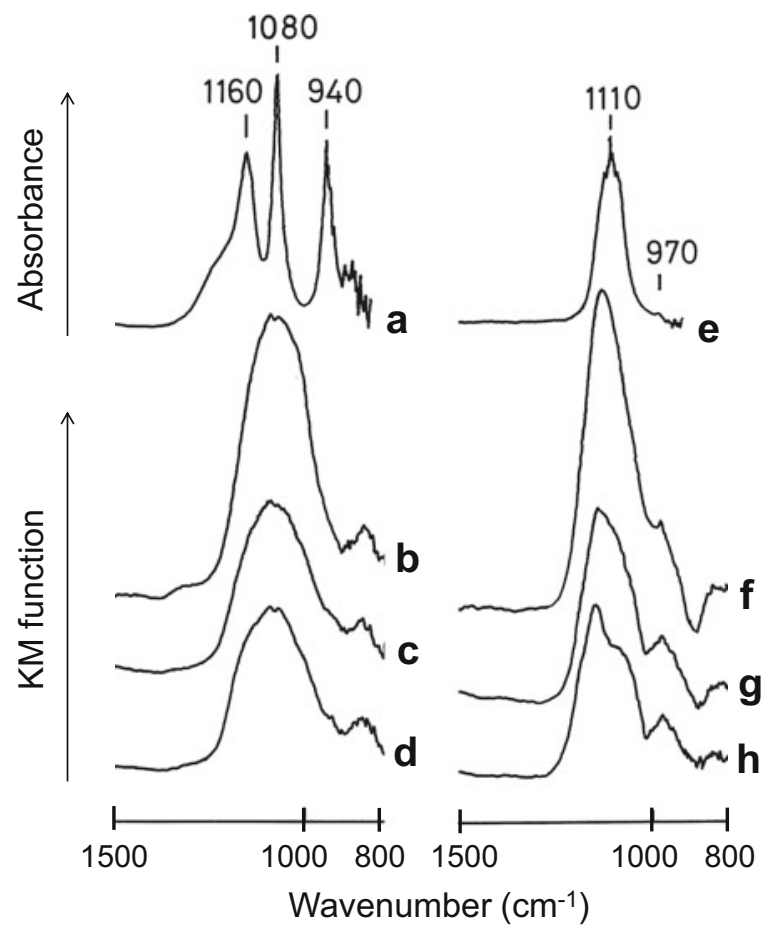

As a $\mathrm{P}$ sorption product is not detectable by XRD, infrared absorption (IR) spectroscopy is effective. Parfitt et al. (1976), Nanzyo and Watanabe (1982), and Nanzyo (1986) used IR spectroscopy to examine P sorption by active Fe materials. In IR spectroscopy, the vibration mode of a molecule, of which the dipole moment changes, is detected. Figure 6.33a is an infrared absorption spectrum of dihydrogen phosphate in water. There are three or more absorption bands related to $\mathrm{P}-\mathrm{O}$ stretching vibration. A distinctive change in the IR spectrum occurred when $\mathrm{P}$ was sorbed by the Al hydroxide gel (Fig. 6.33b). In order to highlight the IR spectrum of sorbed $\mathrm{P}$, a differential method was used in the IR spectroscopy of Fig. 6.33b, c, d, f, g, h. The absorption bands of phosphate were converted to a broad one (Fig. 6.33b) after sorption by the $\mathrm{Al}$ hydroxide gel, suggesting that the product is a material close to noncrystalline aluminum phosphate. The simple and broad IR absorption band changed little under reduced pressure and heating (Fig. 6.33c, d). However, the absorption band is broader than that for noncrystalline aluminum phosphate. The sorbed $\mathrm{P}$ by Al hydroxide gel may have an intermediate property between surface complex and noncrystalline Al phosphate (Nanzyo 1984, 1987, 1988). The IR spectrum of the $P$ accumulated in Andisols as a result of application of P fertilizer is similar to those for Fig. 6.33b, c, d (Nanzyo 1987).

An inverse change is observable for sulfate in water and sorbed sulfate by $\mathrm{Al}$ hydroxide gel. Sulfate shows a rather simple IR absorption band in water (Fig. 6.33e) due to the high symmetry of $\mathrm{SO}_{4}{ }^{2-}$ (Fig. 6.33e), whereas the IR bands of sorbed 


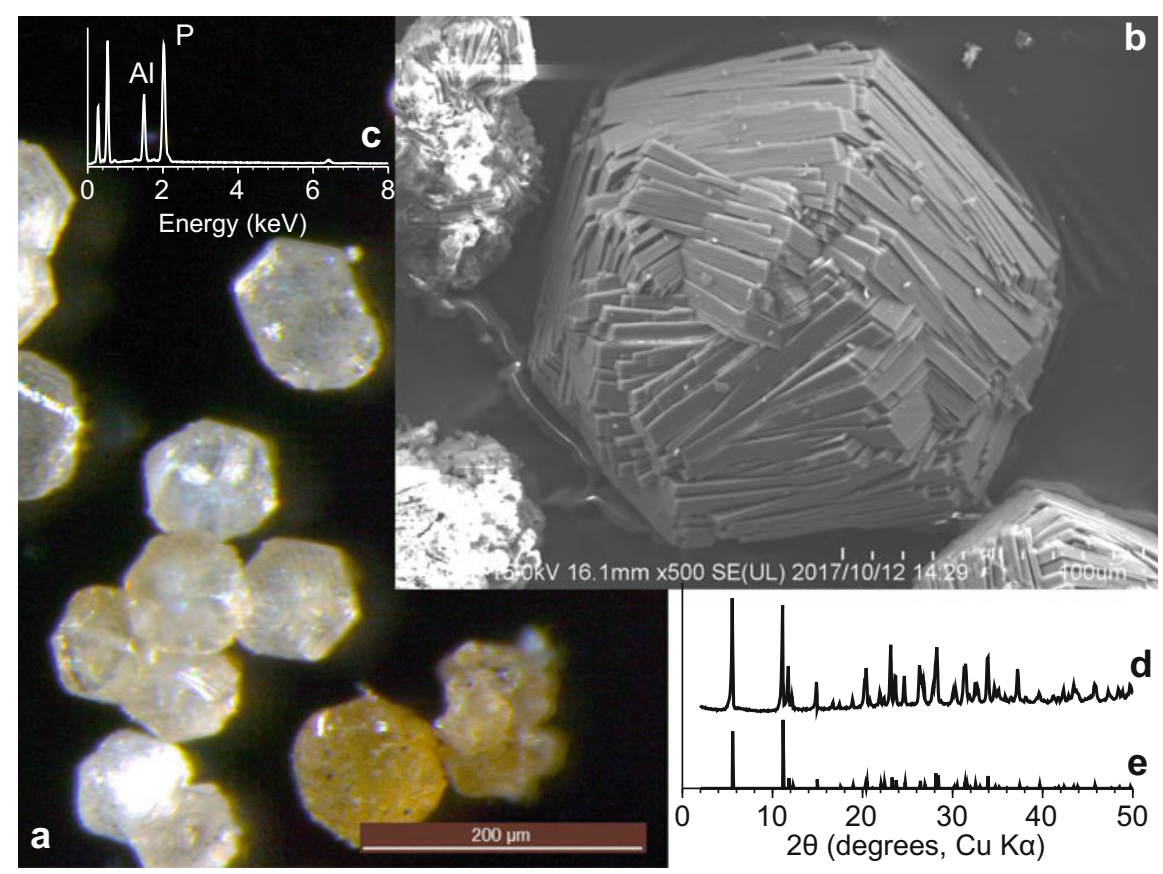

Fig. 6.34 Ammonium taranakite formed from the reaction of an Andisol and ammonium dihydrogen phosphate. (a) Optical micrograph, (b) SEM image, (c) EDX spectrum, (d) XRD pattern of (a), (e) reference XRD pattern (Lehr et al. 1967)

sulfate by the $\mathrm{Al}$ hydroxide gel have an increased degree of splitting with reduced pressure and heating. The symmetry of $\mathrm{SO}_{4}{ }^{2-}$ was reduced with an increase in the interaction between sulfate and the $\mathrm{Al}$ hydroxide gel surface under reduced pressure and heating. As a result, the IR absorption bands of sulfate split (Figs. 6.33f, g, h). The contrasting IR spectral changes between $\mathrm{P}$ and sulfate when sorbed by $\mathrm{Al}$ hydroxide gel is believed to reflect the difference in their reactions with the $\mathrm{Al}$ hydroxide gel.

Taranakite $\left[\mathrm{Al}_{5}\left(\mathrm{NH}_{4}\right)_{3} \mathrm{H}_{6}\left(\mathrm{PO}_{4}\right)_{8} \cdot 18 \mathrm{H}_{2} \mathrm{O}\right]$ is the crystalline product from reactions between $\mathrm{P}$ and soil inorganic constituents (Fig. 6.34) (Wada 1959). Allophanic clays, gibbsite, halloysite, and Andisols can be a source of $\mathrm{Al}$ for taranakite. Figure 6.34a shows an optical micrograph of ammonium taranakite formed from the reaction of an allophanic Andisol and $\mathrm{NH}_{4} \mathrm{H}_{2} \mathrm{PO}_{4}$. To obtain the taranakite particles, the less than $38 \mu \mathrm{m}$ fraction of the Andisol was used for the reaction and the taranakite particles were then separated using a $53 \mu \mathrm{m}$ sieve. The light-brown color of one particle is due to adhesion of fine soil particles. In the EDX spectrum (Fig. 6.34c), the absence of $\mathrm{N}$ is due to the property of the window material of the $\mathrm{X}$-ray detector. The powder XRD pattern (Fig. 6.34d) is identical to that of the reference (Fig. 6.34e). A potassium-substituted phase, $\left[\mathrm{Al}_{5} \mathrm{~K}_{3} \mathrm{H}_{6}\left(\mathrm{PO}_{4}\right)_{8} \cdot 18 \mathrm{H}_{2} \mathrm{O}\right.$ ], also exists. An $\mathrm{NH}_{4} \mathrm{H}_{2} \mathrm{PO}_{4}$ concentration higher than $0.2 \mathrm{~mol} \mathrm{~L}^{-1}$ and an acidic 
$\mathrm{pH}$ of around 4 are needed to form taranakite from Andisols. However, even from cultivated Andisol with high $\mathrm{P}$ accumulation, taranakite is not formed by the addition of $1 \mathrm{~mol} \mathrm{~L}^{-1} \mathrm{NH}_{4} \mathrm{Cl}$ and $\mathrm{pH}$ adjustment.

\subsubsection{Struvite}

Struvite $\left(\mathrm{MgNH}_{4} \mathrm{PO}_{4} \cdot 6 \mathrm{H}_{2} \mathrm{O}\right)$ is a major crystalline phosphate in compost (Komiyama et al. 2013). Swine manure compost and chicken manure compost have a total $\mathrm{P}_{2} \mathrm{O}_{5}$ content of 4-5\%. Cattle manure compost has a lower amount. Struvite plays an important role in recycling $\mathrm{P}$ in the soil-plant system.

Figure $6.35 \mathrm{a}$ shows pelletized swine manure compost. According to the optical micrograph (Fig. 6.35b), the struvite is a colorless transparent crystal. Figure $6.35 \mathrm{c}$ shows an SEM image including the same struvite particle and indicating that the major axis of the crystal is approximately $120 \mu \mathrm{m}$. The dashed square $\mathrm{d}$ in Fig. 6.35c includes $\mathrm{Mg}$ and $\mathrm{P}$, supporting the conclusion that this crystal is struvite, although $\mathrm{N}$ is lacking in the EDX spectrum due to the property of the window material of the

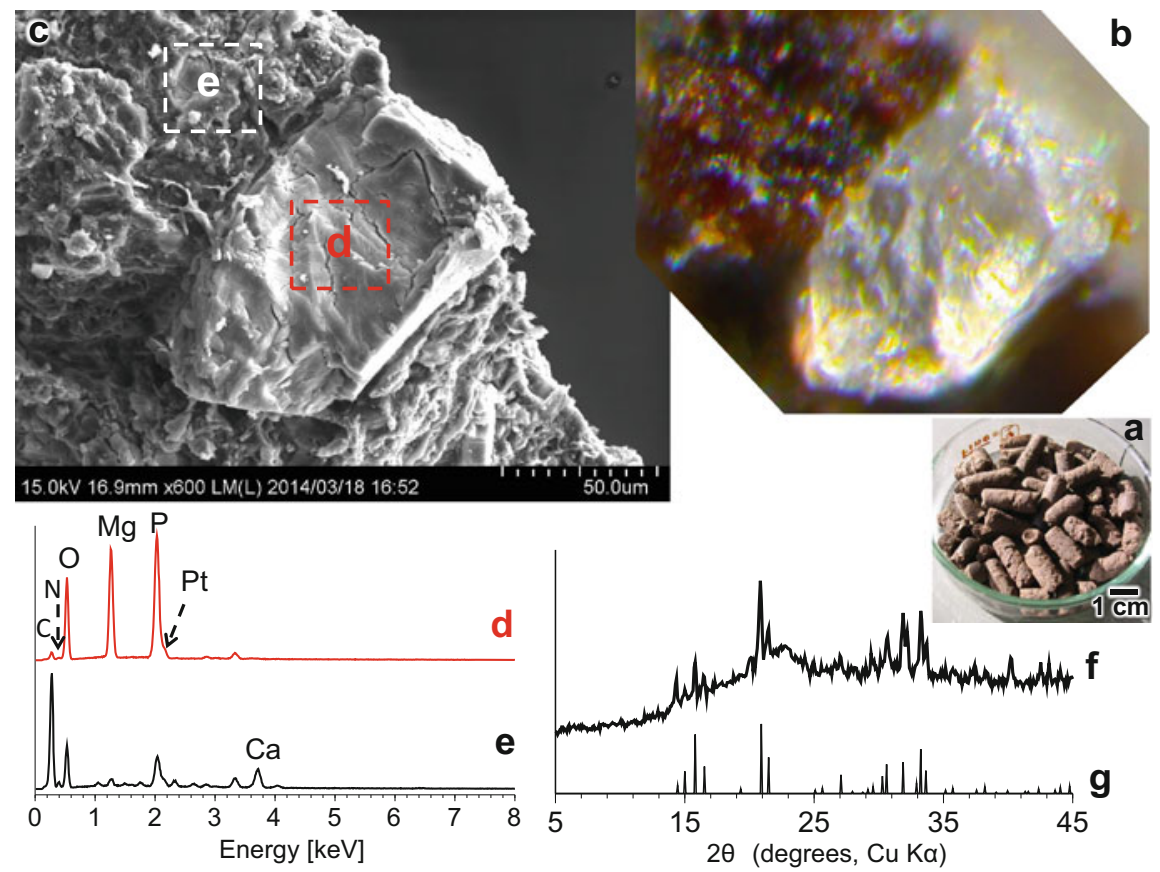

Fig. 6.35 Struvite in pelletized swine manure compost. (a) Fermented and pelletized swine manure (FPSM), (b) optical micrograph of struvite formed in the FPSM, (c) SEM image of a piece of FPSM, (d and e) EDX spectra of dashed areas (d) and (e) in (c), respectively, (f and $\mathbf{g})$ XRD patterns of powdered FPSM and reference struvite (Lehr et al. 1967), respectively 
X-ray detector. The bulk area of the pelletized compost, the other dashed square e of Fig. 6.35c, shows an EDX spectrum with very small peaks for $\mathrm{Mg}, \mathrm{P}, \mathrm{K}$, and $\mathrm{Ca}$. A power XRD pattern obtained from the ground sample (Fig. 6.35f) includes XRD peaks identical to those of the reference struvite (Fig. $6.35 \mathrm{~g}$ ).

\subsubsection{Phosphorus Management in Farmlands}

For sustainable phosphorus management in farmlands, measurement and evaluation of the plant-available $\mathrm{P}$ level in soil and the $\mathrm{P}$ recovery by crop plants is needed. Syers et al. (2008) reviewed several methods for estimating the recovery of phosphorus fertilizers (Fig. 6.36) and stated that the balance method should be re-evaluated despite the frequent use of the difference method. A shortcoming of the difference method is that soils with high residual $\mathrm{P}$ show low recovery percentages whereas the $\mathrm{P}$ uptake by crop plants is not low. In contrast, the $\mathrm{P}$ recovery by the balance method shows high percentages for soils with high residual $\mathrm{P}$.

The plant-available P level in the world's farmlands may be diverse, depending on history of the soil and the fertilizer management. If all of the total P uptake, crop yield, and crop quality are adequate, and the $\mathrm{P}$ recovery rate is $100 \%$ or higher by the balance method, $\mathrm{P}$ application should be adjusted to minimize $\mathrm{P}$ problems, such as fertilizer cost, environmental impact, and dissipation of $\mathrm{P}$ resources. Many paddy

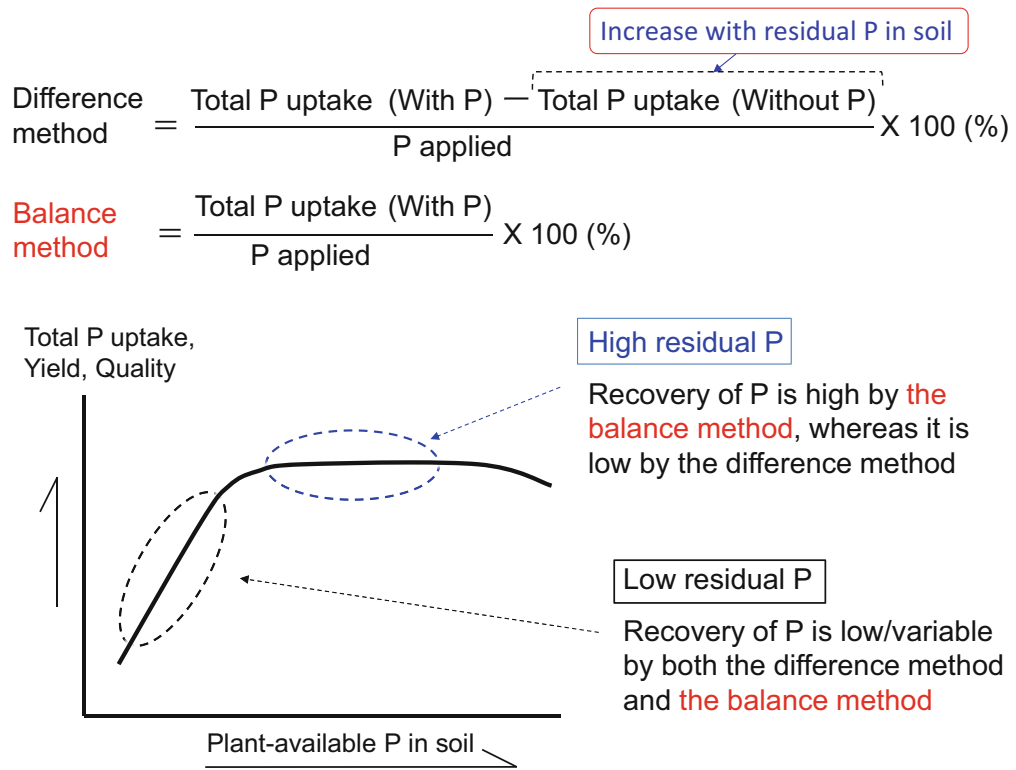

Fig. 6.36 Methods for estimating the recovery of phosphorus fertilizers. (Prepared after Syers et al. 2008) 
field soils in Japan are at this P level, although the plant-available P level increases under reducing conditions (Figs. 5.14 and 5.21). The active Al content in most paddy field soils in Japan is much lower than those of mature Andisols. P management at a $\mathrm{P}$ recovery rate of around $100 \%$ by the balance method can be sustainable.

For farmlands with low plant-available $\mathrm{P}$ and residual $\mathrm{P}, \mathrm{P}$ recovery is low or variable by both the balance and difference methods. The $\mathrm{P}$ recovery rate and the relation between plant-available $\mathrm{P}$ in soil and total $\mathrm{P}$ uptake may vary with soil properties and managements, properties of $\mathrm{P}$ fertilizers, application methods of $\mathrm{P}$ fertilizers, properties of crop plants, and climatic conditions. $\mathrm{P}$ application methods designed to improve $\mathrm{P}$ recovery are needed.

In uncultivated Andisols, the $\mathrm{P}$ concentration of soil water is so dilute that wild plants concentrate $\mathrm{P}$ by an order of $10^{3}$ (Lyu et al. 2016). Many plants obtain dilute $\mathrm{P}$ from soil through a symbiosis with arbuscular mycorrhiza. On the other hand, Brassica plant roots develop as if they were foraging P in Andisol with low plantavailable P (Nanzyo et al. 2002, 2004). Pelletized chicken or swine manure compost (Fig. 6.35a) is suitable $\mathrm{P}$ fertilizer for the phosphorus-foraging root growth of the Japanese radish in this case. Growth of the Japanese radish is normal, and the $\mathrm{P}$ recovery rate is high. Brassica plants are not symbiotic with arbuscular mycorrhiza.

Further readings for phosphorus in soil are Khasawneh et al. (1980), and Sims and Shapley (2005).

\section{References}

Adachi K, Kajimo M, Zaizen Y, Igarashi Y (2013) Emission of spherical cesium-bearing particles from an earyly stage of the Fukushima nuclear accident. Sci Rep 3:2554

Agus F, Tinning G (eds) (2008) International Workshop on Post Tsunami Soil Management, Proceedings 'Lessons learned for agriculture and environmental restoration in the aftermath of the 2004 tsunami, Bogor, Indonesia, 1-2 July 2008, pp 1-177

Amundson R, Berhe AA, Hopmans JW, Olson C, Sztein AE, Sparks DL (2015) Soil and human security in the 21st century. Science 348:6235

Doner HE, Lynn CW (1989) Carbonate, halide, sulfate, and sulfide minerals. In: Dixon JB, Weed SB (eds) Minerals in soil environments, 2nd edn. SSSA, Madison, pp 279-330

Edixhoven JD, Gupta J, Savenije HHG (2014) Recent revisions of phosphate rock reserves and resources: a critique. Earth Syst Dynam 5:491-507

Endo T, Yamamoto S, Honna T, Eneji AE (2002) Sodium-calcium exchange selectivity as influenced by clay minerals and composition. Soil Sci 167:117-125

Ericksen J (2009) Soil sulfur cycling in temperate agricultural systems. Adv Agron 102:55-89

Evangelow VP, Phillips RE (2005) Cation exchange in soils. In: Chemical processes in soils, SSSA book series, no.8. SSSA, Madison, pp 343-409

Evrard O, Chartin C, Onda Y, Lepage H, Cerdan O, Lefevre I, Ayrault S (2014) Renewed soil erosion and remobilization of radioactive sediment in Fukushima coastal rivers after the 2013 typhoons. Sci Rep 4:4574

Geospacial Information Authority of Japan (2014) Extension site of distribution map of radiation dose, etc. http://ramap.jmc.or.jp/map/eng/

Green TH, Watson EB (1982) Crystallization of apatite in natural magmas under high pressure, hydrous conditions, with particular reference to 'orogenic' rock series. Contrib Mineral Petrol 79:96-105 
Hirose K (2016) Fukushima Daiichi nuclear plant accident: atomospheric and oceanic impacts over the five years. J Environ Radioact 157:113-130

Inao E, Kamiyama K, Moriya K, Konno C, Onodera K, Shima H, Ito T, Kanno H (2013) Chemical property of tsunami sediment deposited following the East Japan great earthquake (south part of Miyagi Prefecture). Agric Hortic Res Inst Res Rep 81:63-87 (In Japanese with English summary)

Ippolito JA, Barbarick KA, Elliott HA (2011) Drinking water treatment residuals: a review of recent uses. J Environ Qual 40:1-12

Kamphorst A, Bolt GH (1976) Saline and sodic soils. In: Bolt GH, Bruggenwert MGM (eds) Soil chemistry A. Basic elements, developments in soil science 5A. Elsevier, Amsterdam/ Oxford/New York, pp 171-191

Kanno H (2017) Impact of the 2011 Tohoku-oki earthquake tsunami on cultivated oils in Miyagi Prefecture, northeastern Japan: an overview. In: Santiago-Fandino V et al (eds) The 2011 Japan earthquake and tsunami: reconstruction and resortation, Advances in natural and technological hazards research, vol 47. Springer, Dordrecht, pp 341-354

Kanno H, Nanzyo M, Takahashi T (2013) Tour guide of 60th field trip of Japanese Society of Pedology, pp 62-73

Khasawneh FE, Sample EC, Kamprath EJ (1980) The role of phosphorus in agriculture. ASA-CSSA-SSSA, Madison

Komiyama T, Niizuma S, Fujisawa E, Morikuni (2013) Phosphorus compounds and their solubility in swine manure compost. Soil Sci Plant Nutr 59:419-426

Kopittke PM, So HB, Menzies NW (2006) Effect of ionic strength and clay mineralogy on Na-ca exchange and the SAR-ESP relationship. Eur J Soil Sci 57:626-633

Lehr JR, Brown EH, Frazier AW, Smith JP, Thrasher RD (1967) Crystallographic properties of fertilizer compounds. Chemical engineering bulletin 6. Tennessee Valley Authority, Knoxville, $\mathrm{TN}$

Lyu Y, Tang H, Li H, Zhang F, Rengel Z, Whalley WR, Shen J (2016) Major crop species show differential balance between root morphological and physiological responses to variable phosphorus supply. Front Plant Sci 7:1939

McBride MB (1989) Surface chemistry of soil minerals. In: Dixon JB, Weed SB (eds) Minerals in soil environments, SSSA book series no.1. SSSA, Madison, pp 35-88

Miller WP, Frenkel H, Newman KD (1990) Flocculation concentration and sodium-calcium exchange of kaolinitic soil clays. Soil Sci Soc Am J 54:346-351

Ministry of Agriculture, Forestry and Fisheries Japan (2012) FY2011 annual report on food, agriculture and rural areas in Japan, Summary

Minoura K, Imamura F, Sugawara D, Kono Y, Iwashita T (2001) The 869 Jogan tsunami deposit and recurrence interval of large-scale tsunami on the Pacific coast of Northeast Japan. J Nat Disaster Sci 23:83-88

Monecke K, Finger W, Klarer D, Kongko W, McAdoo BG, Moore AL, Sudrajat SU (2008) A 1,000-year sediment record of tsunami recurrence in northern Sumatra. Nature 455:1232-1234

Mukai H, Hirose A, Motai S, Kikuchi R, Tanoi K, Nakanishi T, Yaita T, Kogure T (2016) Cesium adsorption/desorption behavior of clay minerals considering actual contamination conditions in Fukushima. Sci Rep 6:21543

Nakamaru Y, Nanzyo M, Yamasaki S (2000) Utilization of apatite in fresh volcanic ash by Pigeonpea and chickpea. Soil Sci Plant Nutr 46:591-600

Nakanishi T, Tanoi K (eds) (2013) Agicultural implicaitons of the Fukushima nuclear accident. Springer, Tokyo

Nakanishi T, Tanoi K (eds) (2016) Agicultural implicaitons of the Fukushima nuclear accident: the first three years. Springer, Tokyo

Nakao A, Ogasawara S, Sano O, Ito T, Yanai J (2014) Radiocesium sorption in relation to clay mineralogy of paddy soils in Fukushima, Japan. Sci Total Environ 468:523-529

Nakaya T, Tanji H, Kiri H, Hamada H (2010) Developing a salt-removal plan to remedy Tsunamicaused salinity damage to farmlands: Case study for an area in Southern Thailand. JARQ, 44: $159-165$ 
Nanzyo M (1984) Diffuse reflectance infrared spectra of phosphate sorbed on alumina gel. J Soil Sci 35:63-69

Nanzyo M (1986) Infrared spectra of phosphate sorbed on iron hydroxide gel and the sorption products. Soil Sci Plant Nutr 32:51-58

Nanzyo M (1987) Formation of noncrystalline aluminum phosphate through phosphate sorption on allophanic ando soils. Commun Soil Sci Plant Anal 18:735-742

Nanzyo M (1988) Phosphate sorption on the clay fraction of Kanuma pumice. Clay Sci 7:89-86

Nanzyo M (2012) Impacts of tsunami (March 11, 2011) on paddy field soils in Miyagi Prefecture, Japan. J Integr Field Sci 9:3-10

Nanzyo M, Watanabe Y (1982) Diffuse reflectance infrared spectra and ion-adsorption properties of the phosphate surface complex on goethite. Soil Sci Plant Nutr 28:359-368

Nanzyo M, Yamasaki S (1998) Phosphorus bearing mineral in fresh, andesite and rhyolite tephras in northern part of Japan. Phosphorus Res Bull 8:95-100

Nanzyo M, Takahashi T, Sato A, Shoji S, Yamada I (1997) Dilute acid-soluble phosphorus in fresh air-borne tephras and fixation with an increase in active aluminum and iron. Soil Sci Plant Nutr 43:839-848

Nanzyo M, Nakamaru Y, Yamasaki S (1999) Inhhibition of apatite dissolution due to formation of calcium o xalate coating. Phosphorus Res Bull 9:17-22

Nanzyo M, Shibata Y, Wada N (2002) Complete contact of Brassica roots with phosphates in a phosphorus-deficient soil soil Sci. Plant Nutr 48(6):847-853

Nanzyo M, Ebuchi Y, Kanno H (2003) Apatite in the pyroclastic flow deposits (1990-1995) of the Unzen volcano, Japan, and its utilization by buckwheat. Phosphorus Res Bull 16:1-10

Nanzyo M, Wada N, Kanno H (2004) Phosphorus foraging root development of Brassica rapa nothovar. grown in a phosphorus-deficient nonallophanic. Andisol Plant Soil 265:325-333

Nanzyo M, Kanno H, Takeda A (2014) Vertical distribution of radiocesium in side bar deposits of the Utsushi and Agano rivers, Japan. Clay Sci 18:43-52

Nanzyo M, Takeda A, Hio A, Ito K, Kanno H, Takahashi T (2015) Vertical distribution of radocaesium in tsunami-affected farmland soils in Miyagi Prefecture, Japan. Icobte 2015 Fukuoka abstract book, 13th international conference on the biogeochemistry of trace elements, July 12-16, 2015, Fukuoka International Congress Center, Fukuoka, Japan

Niigata City (2014) Radioactive elements in water treatment residual generated in Aaganogawa water purification plant. http://www.city.niigata.lg.jp/kurashi/jyogesuido/suido/sinsai/tuti_ chosa/aganogawa.html

Norio O, Ye T, Kajitani Y, Shi PJ, Tatano H (2011) The 2011 eastern Japan great earthquake disaster: overview and comments. Int J Disaster Risk Sci 2:34-42

Oda K, Miwa E, Iwamoto A (1987) Compact database. Jpn J Soil Sci Plant Nutr 61:112-131 (In Japanese)

Ohwaki Y, Hirata H (1992) Differences in carboxylic acid exudation among P-starved leguminous crops in relation to carboxylic acid contents in plant tissues and phospholipid level in roots. Soil Sci Plant Nutr 38:235-243

Okal EA (2011) Tsunamigenic earthquakes: past and present milestones. Pure Appl Geophys 168:969-995

Parfitt RL, Russell JD, Farmer VC (1976) Confirmation of the surface structures of goethite $(\alpha-\mathrm{FeOOH})$ and phosphate goethite by infrared spectroscopy. J Chem Soc, Faraday I 72:1082-1087

Saitama Prefecture (2014) Radioactivity of water treatment residual generated in water purification plant. http://www.pref.saitama.lg.jp/page/hasseido-sokuteikekka.html

Saito K, Shimbori T, Draxler R (2015) JAM's regional atmospheric transport model calculations for the WMO technical task team on meteorological analyses for Fukushima Daiichi nuclear power plant accident. J Environ Radioact 139:185-199

Satake K, Rabinovich A, Kanoglu U, Tinti T (2011) Introduction to "tsunamis in the World Ocean: past, present, and future. Volume I". Pure Appl Geophys 168:963-968 
Shainberg I, Oster JD, Wood JD (1980) Sodium=calcium exchange in montmorillonite and illite suspensions. Soil Sci Soc Am J 44:960-964

Shima H, Onodera K, Kanazawa Y, Satoh K, Onodera H, Abe T, Wakashima A, Inao E, Moriya K, Konno C, Kamiyama K, Itoh T, Kanno H (2012) Chemical property of tsunami sediment deposited following the East Japan great earthquake (northern part of Miyagi Prefecture). Bull Miyagi Prefectural Furukawa Agric Exp Station 10:33-42 (In Japanese with English summary)

Shiozawa S (2013) Vertical migration of radiocesium fallout in soil in Fukushima. In: Nakanishi TM, Tanoi K (eds) Agricultural implications of the Fukushima nuclear accident. Springer, Tokyo/Heiderberg/New York/Dordrecht/London, pp 49-60

Sims JT, Sharpley AN (2005) Phosphorus: agriculture and the environment. No.46 in the series Agronomy. ASA-CSSA-SSSA, Madison

Srisutam C, Wagner J-F (2010) Tsunami sediment characteristics at the Thai Andaman Coast. Pure Appl Geophys 167:215-232

Steinhauser G, Brandl A, Johnson TE (2014) Comparison of the Chernobyl and Fukushima nuclear accidents: a review of the environmental impacts. Sci Total Envron 470-471:800-817

Syers K, Johnston E, Curtin D (2008) Efficiency of soil and fertilizer phosphorus: reconciling changing concepts of soil phosphorus behavior with agronomic information, FAO fertilizer and plant nutrition bulletin 18. FAO, Rome

Szczuciński W, Kokociński M, Rzeszewski M, Chague-Goff C, Cachao M, Goto K, Sugawara D (2012) Sediment sources and sedimentation processes of 2011 Tohoku-oki tsunami deposits on the Sendai Plain, Japan-Insights from diatoms, nannoliths and grain size distribution. Sediment Geol 282:40-56

Thomas G (1982) Exchangeable cations. In: Methods of soil analysis part 2, Chemical and microbiological properties, 2nd edn. ASA-SSSA, Madison, pp 159-165

Tsukada H, Takeda A, Hisamatsu S, Inaba J (2008) Concentration and specific activity of fallout ${ }^{137}$ Cs in extracted and particle-size fractions of cultivated soils. J Environ Radioact 99:875-881

U.S. Salinity Laboratory Staff (1954) Diagnosis and improvement of saline and alkali soils. In: USDA agriculture handbook 60. U.S. Government Printing Office, Washington, DC, pp 25-30

Vorob'eva LA, Pankova EI (2008) Saline-alkali soils of Russia. Eurasian Soil Sci 41:517-532

Wada K (1959) Reaction of phosphate with allophane and halloysite. Soil Sci 87:325-330

Yomiuri News Paper (2011) Cesium of water treatment residual generated from Aganogawa water purification plant. https://database.yomiuri.co.jp/ rekishikan/ (August, 2014)

Open Access This chapter is licensed under the terms of the Creative Commons Attribution 4.0 International License (http://creativecommons.org/licenses/by/4.0/), which permits use, sharing, adaptation, distribution and reproduction in any medium or format, as long as you give appropriate credit to the original author(s) and the source, provide a link to the Creative Commons license and indicate if changes were made.

The images or other third party material in this chapter are included in the chapter's Creative Commons license, unless indicated otherwise in a credit line to the material. If material is not included in the chapter's Creative Commons license and your intended use is not permitted by statutory regulation or exceeds the permitted use, you will need to obtain permission directly from the copyright holder. 